\title{
Model predictions of long-lived storage of organic carbon in river deposits
}

\author{
Mark A. Torres ${ }^{1}$, Ajay B. Limaye ${ }^{2}$, Vamsi Ganti ${ }^{3}$, Michael P. Lamb ${ }^{1}$, A. Joshua West ${ }^{4}$, and \\ Woodward W. Fischer ${ }^{1}$ \\ ${ }^{1}$ Division of Geological \& Planetary Sciences, California Institute of Technology, Pasadena, CA, USA \\ ${ }^{2}$ Department of Earth Sciences, University of Minnesota, Minneapolis, MN, USA \\ ${ }^{3}$ Department of Earth Science \& Engineering, Imperial College London, London, England \\ ${ }^{4}$ Department of Earth Sciences, University of Southern California, Los Angeles, CA, USA \\ Correspondence to: Mark A. Torres (mt61@ rice.edu)
}

Received: 3 May 2017 - Discussion started: 15 May 2017

Revised: 2 August 2017 - Accepted: 12 September 2017 - Published: 3 November 2017

\begin{abstract}
The mass of carbon stored as organic matter in terrestrial systems is sufficiently large to play an important role in the global biogeochemical cycling of $\mathrm{CO}_{2}$ and $\mathrm{O}_{2}$. Field measurements of radiocarbon-depleted particulate organic carbon (POC) in rivers suggest that terrestrial organic matter persists in surface environments over millennial (or greater) timescales, but the exact mechanisms behind these long storage times remain poorly understood. To address this knowledge gap, we developed a numerical model for the radiocarbon content of riverine POC that accounts for both the duration of sediment storage in river deposits and the effects of POC cycling. We specifically target rivers because sediment transport influences the maximum amount of time organic matter can persist in the terrestrial realm and river catchment areas are large relative to the spatial scale of variability in biogeochemical processes.

Our results show that rivers preferentially erode young deposits, which, at steady state, requires that the oldest river deposits are stored for longer than expected for a well-mixed sedimentary reservoir. This geometric relationship can be described by an exponentially tempered power-law distribution of sediment storage durations, which allows for significant aging of biospheric POC. While OC cycling partially limits the effects of sediment storage, the consistency between our model predictions and a compilation of field data highlights the important role of storage in setting the radiocarbon content of riverine POC. The results of this study imply that the controls on the terrestrial OC cycle are not limited to the factors that affect rates of primary productivity and respiration but also include the dynamics of terrestrial sedimentary systems.
\end{abstract}

\section{Introduction}

Terrestrial organic matter present in the biosphere, soils, and other shallow sedimentary deposits represents an enormous reservoir of carbon (4 to $5 \times 10^{12} \mathrm{tC}$; Fischlin et al., 2007) whose dynamics influence atmospheric $\mathrm{O}_{2}$ and $\mathrm{CO}_{2}$ concentrations over annual (Keeling, 1960; Keeling and Shertz, 1992; Stallard, 1998) to geologic timescales (Bird et al., 1994; France-Lanord and Derry, 1997). Understanding the links between terrestrial organic carbon (OC) cycling and atmospheric $\mathrm{O}_{2}$ and $\mathrm{CO}_{2}$ concentrations requires knowledge of the timescales over which OC persists in the environment before being oxidized (Berner, 1989) as well as the underlying processes that set these timescales. Identifying these processes and timescales is challenging because existing measurements of OC lifetimes show scale dependence (i.e., the measured rate of organic carbon oxidation decreases with increasing measurement timescale; Middelburg, 1989; Katsev and Crowe, 2015). Consequently, measurements of terrestrial OC cycling need to be made at large spatial and temporal scales to be quantitatively linked to global biogeochemical cycles. 
Large rivers integrate the dynamics of OC cycling at spatial and temporal scales large enough to relate to global biogeochemical cycles. Rivers transport particulate OC (POC) eroded from across their catchment areas to the ocean, where POC is either oxidized or buried in marine sediments (Blair and Aller, 2012). Thus, rivers influence the amount of time POC can persist within the terrestrial realm and integrate over areas that are large compared to the spatial scales of variability in biogeochemical processes. Annually, rivers transport large masses of POC to the ocean (1 to $2 \times 10^{8} \mathrm{tC} \mathrm{yr}^{-1}$; Galy et al., 2015), making fluvial transport a relevant carbon cycle flux over a range of timescales.

At the scale of river catchments, radiocarbon $\left({ }^{14} \mathrm{C}\right)$ provides a natural tracer of the lifetime of OC in surface environments. Previous studies have measured large variations in the ${ }^{14} \mathrm{C} /{ }^{12} \mathrm{C}$ of riverine POC (Masiello and Druffel, 2001; Martin et al., 2013; Clark et al., 2013; Tao et al., 2015), including significant variations in ${ }^{14} \mathrm{C} /{ }^{12} \mathrm{C}$ with depth in river channels (Galy et al., 2008; Bouchez et al., 2010, 2014). Direct interpretation of measured ${ }^{14} \mathrm{C} /{ }^{12} \mathrm{C}$ in terms of ages would imply that most riverine POC is old (thousands to tens of thousands of years). However, much of the variation in ${ }^{14} \mathrm{C} /{ }^{12} \mathrm{C}$ has been interpreted in the context of variable admixtures of two carbon components: radiocarbon-bearing organic compounds synthesized within the river catchment ("biospheric" POC) and radiocarbon-dead organics derived from the erosion of ancient sedimentary rocks ("petrogenic" POC; Masiello and Druffel, 2001; Galy et al., 2008).

The erosion of petrogenic POC need not affect the atmospheric budgets of $\mathrm{CO}_{2}$ and $\mathrm{O}_{2}$ unless it is oxidized during transit (Bouchez et al., 2010), which releases $\mathrm{CO}_{2}$ to and consumes $\mathrm{O}_{2}$ from the atmosphere. Conversely, biospheric POC is a sink for $\mathrm{CO}_{2}$ and source of $\mathrm{O}_{2}$ over the course of its lifetime, which is thought to vary widely between different compound classes and environments (Schmidt et al., 2011). While the lifetime of biospheric POC should be reflected in its ${ }^{14} \mathrm{C} /{ }^{12} \mathrm{C}$, determining this ratio from bulk radiocarbon measurements of riverine sediments may be complicated by the mixing of biospheric POC $\left({ }^{14} \mathrm{C} /{ }^{12} \mathrm{C} \leq\right.$ atmospheric ratio) with petrogenic POC $\left({ }^{14} \mathrm{C} /{ }^{12} \mathrm{C}=0\right)$.

Compound-specific radiocarbon analyses of terrestrial biomarkers, which can be interpreted as dominantly reflecting the biospheric component, suggest that biospheric POC has a substantially lower ${ }^{14} \mathrm{C} /{ }^{12} \mathrm{C}$ than the atmosphere in some large river systems (Galy and Eglinton, 2011; Feng et al., 2013; Tao et al., 2015; Schefuß et al., 2016). These observations require that some biospheric POC is stored in terrestrial reservoirs over (at least) millennial timescales before being transported to ultimate depocenters in marine basins. It is reasonable to ask whether these observations of aged biospheric POC in modern rivers result, at least in part, from transient storage in river sediment deposits (Galy and Eglinton, 2011; Feng et al., 2013; Tao et al., 2015; Schefuß et al., 2016).
To investigate how storage in river deposits influences the ${ }^{14} \mathrm{C}$ content of riverine POC, we developed a numerical model that explicitly accounts for the effects of both sediment storage and OC cycling. The sediment storage component of our model is focused on how the stochastic nature of fluvial processes leads to the preferential recycling of young sediment deposits (Nakamura and Kikuchi, 1996; Bradley and Tucker, 2013), which, at steady state, requires that the oldest deposits are stored for longer than expected for a well-mixed sedimentary reservoir (Bolin and Rodhe, 1973; Bradley and Tucker, 2013). This geometric relationship engenders a heavy-tailed (power-law) distribution of sediment storage durations that may allow for the significant aging of biospheric POC during storage in river deposits and impart a characteristic shape to the distribution of POC ages measured in rivers. However, the production and consumption of POC during floodplain storage can modify POC ages and may serve to limit the effects of sediment storage on the POC age distribution. By including both fluvial and biogeochemical processes, our approach provides new insights into the interpretation of the terrestrial OC cycle and the radiocarbon content of riverine POC.

Starting from a generic theory for predicting the duration of sediment storage in river systems (Sect. 2.1), we developed a sediment storage model based on the dynamics of meandering rivers (Sect. 2.2 and 2.3). We coupled this sediment storage model to a biogeochemical cycling model (Sect. 2.4) in order to build a full model for predicting the radiocarbon content of riverine POC under different sedimentary and biogeochemical scenarios. Predictions generated using this coupled model were compared with a compilation of field data from diverse global sites, demonstrating that the dynamics of sediment storage in shallow deposits have significant predictive skill in explaining - at least in part - the radiocarbon content of organic matter observed within many rivers (Sect. 3.3.1).

\section{Model development}

\subsection{Generic theory for organic carbon and sediment storage}

After being eroded from an upland source, fluvial sediments are routed through a transport network that includes multiple temporary storage reservoirs (e.g., channel and floodplain deposits; Malmon et al., 2003; Lauer and Parker, 2008a; Lauer and Willenbring, 2010; Pizzuto et al., 2017). These sediment reservoirs can also store POC, potentially leading to a decrease in its radiocarbon content due to radioactive decay. The magnitude of this effect will depend on (1) the duration of sediment storage and (2) the rate at which the ${ }^{14} \mathrm{C}$ content of POC changes with time. Developing simple models for these two factors forms the basis of our approach.

Sediment grains will spend some portion of their time in transient storage within sediment deposits and the remain- 
der of their time in active transport associated with the river channel. We posit that the time spent in storage is much greater than the time spent in active transport (e.g., Sadler, 1981; Ganti et al., 2011) and, as a result, that the total transit time of sediments from source to sink can be approximated as the total time spent in storage. Since sediment grains likely enter and exit temporary storage reservoirs multiple times during transit, the total storage time can be separated into two components: (1) the number of times that grains enter and exit storage reservoirs and (2) the duration of each storage event.

Fluvial processes are expected to cause natural variations in the duration of each storage event. This variability can be simulated by representing the duration of a single storage event as a random variable with some probability distribution $p_{S}(\mathrm{t})$. Thus, for some number of storage events $n$, the cumulative age, or transit time, of the sediment can be calculated as the sum of $n$ draws from the probability distribution of storage durations. Since the sediment load transported by rivers is composed of a collection of sediment grains with different storage histories, it will be characterized by some distribution of transit times that reflects both $p_{S}(t)$ and the total number of storage events. Mathematically, the transit time distribution of this collection of grains $\left(p_{\mathrm{Tr}}(t)\right)$, which is the distribution function for the sum of $n$ random values drawn from $p_{S}(t)$, is given by the convolution of the storage duration distribution by itself $n$ times:

$p_{\operatorname{Tr}}(t)=p_{S}(t)^{* n}$

To predict the change in the radiocarbon content of POC that results from sediment storage, the inverse of the functional relationship between the radiocarbon content of POC and time, ${ }^{14} \mathrm{C}=f(t)$, can be used to transform the transit time distribution into a distribution of radiocarbon contents $\left(p_{F}\left({ }^{14} \mathrm{C}\right)\right)$ where

$p_{F}\left({ }^{14} \mathrm{C}\right)=p_{\operatorname{Tr}}\left(f^{-1}\left({ }^{14} C\right)\right) \frac{\mathrm{d} t}{\mathrm{~d}^{14} \mathrm{C}}$.

We note that, while $f(t)$ must be monotonic, it need not be the radioactive decay equation if POC is continuously produced and consumed during fluvial transit, which is considered in greater detail in Sect. 2.4.2.

\subsection{Application of a meandering model to determine storage duration}

Identifying appropriate mathematical expressions for the probability distribution of storage durations is critical to developing realistic models for several geochemical tracers in river sediments, including the radiocarbon content of POC, that have nonlinear changes in concentration with time. Most previous models of sediment storage in meandering river systems have assumed that storage durations are exponentially distributed (Malmon et al., 2003; Lauer and Parker, 2008a;
Lauer and Willenbring, 2010). This assumption requires that deposits of all ages are equally likely to be eroded at any given time, which is inconsistent with some field data (Nakamura and Kikuchi, 1996; Lancaster and Casebeer, 2007) as well as the common observation that the position of the river channel is persistent in time (Bradley and Tucker, 2013). To develop a more realistic storage duration distribution, it is necessary to consider the physical processes that govern sediment exchange in natural river systems.

In lieu of following a static path, many rivers migrate laterally across their floodplains with time. Single-thread, migrating (i.e., meandering) channels are one of the most common channel types and show morphodynamic processes common to all alluvial rivers (Dunne and Aalto, 2013). Over time, lateral migration of single-thread rivers leads to the development of arcuate meander bends. Meander bends can grow until a cutoff event occurs where the river bypasses an existing portion of its reach in favor of a straighter path (e.g., Hooke, 1995). Together, lateral migration and cutoff allow rivers to traverse back and forth across their floodplains over time and continuously exchange sediments in active transport with those in passive storage. Thus, the spatial and temporal patterns of lateral migration and cutoff directly impact the duration of sediment storage in fluvial systems (Bradley and Tucker, 2013).

In order to capture the full range of relevant time and space scales, which are unavailable in existing field observations of lateral migration (Black et al., 2010; Constantine et al., 2014), we used an established numerical model of river meandering (Howard and Knutson, 1984; Limaye and Lamb, 2013) to derive a process-based probability distribution of storage durations. The meandering model assumes a fixed channel width and represents the channel position using a series of discrete nodes. The channel is inset in a planar floodplain surface and migrates laterally with no bed elevation change. The model domain extends for 125 channel widths in the mean downstream direction and is unconstrained in the mean cross-stream direction. At each node, local rates of relative channel migration are calculated based on the local and upstream-weighted channel curvature. Smoothly curving meander bends initially develop from small perturbations in the channel centerline trace and migrate at rates that vary in both space and time. Absolute migration rates are computed from the relative channel migration rate, sinuosity, and a user-defined bank erodibility coefficient, which sets average lateral migration rate for each simulation. Neck cutoffs occur whenever the channel intersects itself; chute cutoffs are not modeled. We fixed the maximum channel lateral erosion rate at 0.05 channel widths per year, which is typical for actively migrating meandering rivers (e.g., Hickin and Nanson, 1975; Constantine et al., 2014), and ran each model simulation for a total of $10^{5}$ years. We neglect overbank deposition and the loss of sediment due to subsidence but discuss these in Sect. 4.1. A schematic of the model is shown in Fig. 1. 

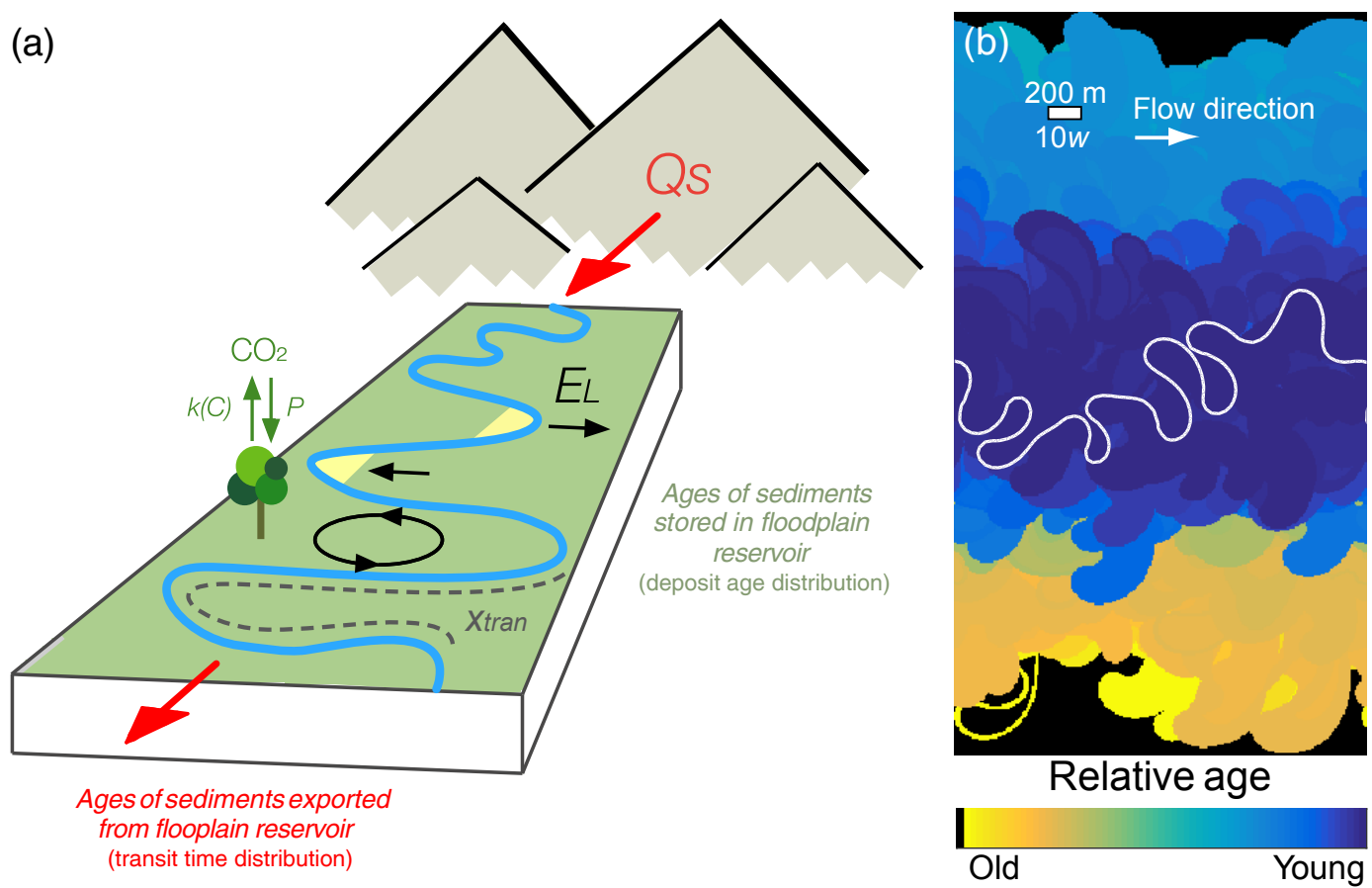

Figure 1. Model schematics highlighting key geometric relationships. (a) The sediment flux $\left(Q_{\mathrm{S}}\right)$ from an upstream area is routed though an alluvial valley. As a result of lateral channel migration $\left(E_{\mathrm{L}}\right)$, sediment deposits are created and eroded leading to transient sediment storage. During sediment storage, the fixation of atmospheric $\mathrm{CO}_{2}$ by biota leads to the production $(P)$ of particulate organic carbon $(C)$, which is degraded back to $\mathrm{CO}_{2}$ at a rate $(k)$ proportional to its concentration in sediments. As sediments (and POC) move downstream, they can be re-deposited and stored. Here, we define a characteristic length scale $\left(x_{\text {tran }}\right)$ that reflects the distance sediments travel before being re-deposited. The ages of sediments and organic carbon can be described by two distributions. The transit time distribution describes the ages of material being actively removed from the system by erosion and thus have reached maximum age. The deposit age distribution describes the ages of material that remains stored in river deposits and will continue to age until subsequent erosion. (b) A map view of example model output where the white line shows the final position of the river channel, which flows from left to right across the model domain. Sediment ages range from relatively old (yellow and orange) at the lower edge of the domain to relatively young (blue) nearer the channel. Areas of the model domain not visited by the channel are shaded black.

The numerical model runs yield a time series of channel positions. For all time steps, we define areas within the active channel as having a sediment age of zero. As time proceeds and the channel migrates, it abandons sediments along the inner bank (i.e., point bar deposits), which begin to age. When the active channel overlaps existing deposits, the time elapsed since the emplacement of those deposits is recorded as the storage duration. Since areas bounded by the channel are defined as having a sediment age of zero, the model does not allow for cumulative aging as a result of multiple deposition and transport events (i.e., once material is eroded, its age is reset to zero). As a consequence, the model does not measure the total amount of time sediments spend in storage (transit time) but instead tracks the amount of time spent in storage for a single deposition/erosion event (storage duration).

Using the time series of channel positions, we calculated storage durations as the ages of river deposits that are eroded by lateral migration at each time step. The storage dura- tion for each eroded deposit is weighted by its areal extent along the active channel, and observations from each time step were combined to yield a full distribution of storage durations for the model. Thus, we consider only the time-averaged behavior of the model under steady conditions without any additional forcing. We note that excluding data from the beginning (e.g., the first $50 \%$ ) of the model runs does not significantly affect the full distribution since short storage durations are more probable overall. We also examined the age distribution of deposits remaining on the floodplain at the end of the model run, which we termed the deposit age distribution.

Our approach of using a numerical model of river meandering is similar to that of Bradley and Tucker (2013), who developed a quasi-static storage duration distribution from a single meandering model simulation. The river meandering model used in this study (Howard and Knutson, 1984) differs from the Lancaster and Bras (2002) model used by Bradley and Tucker (2013). A salient difference between the models 
is that only the Lancaster and Bras (2002) model has been shown to develop compound bends prior to cutoff. However, similar bend geometries rapidly develop in the Howard and Knutson (1984) model due to meander cutoff. Also, compared to Bradley and Tucker (2013), our analysis uses a suite of model runs with periodic boundary conditions that allow freer channel motion, including drift of the mean channel axis (Limaye and Lamb, 2013). To systematically account for the sensitivity of the meandering model to the initial channel planform geometry, which can impact modeled river trajectories (e.g., Frascati and Lanzoni, 2009), we used 50 replicate model runs to determine deposit age distributions. We used a subset of five replicate simulations to determine storage duration distributions. Different initial channel centerlines for the replicate model runs were generated by adding random perturbations on the order of 0.01 channel widths to otherwise straight channels. These perturbations also initiate meandering in the model runs.

\subsubsection{Scaling model results to natural systems}

Our meandering model simulations should capture the appropriate shape of the storage duration distribution. However, absolute values vary as a function of the lateral migration rate. Specifically, rivers that migrate quickly should have, on average, shorter storage durations relative to rivers that migrate slowly. In order to account for the effects of variable migration rates, we normalized all storage durations by the time required for the channel to migrate laterally to the point of meander bend cutoff ( $\left.T_{\text {cut }}\right)$. In our model simulations, we explicitly tracked meander bends from growth to cutoff following the approach of Schwenk et al. (2015). While the cutoff time varied in the model runs, the peak of the probability distribution function occurred for $T_{\text {cut }}=350$ years. Normalizing the meandering model results by this $T_{\text {cut }}$ value yields a dimensionless storage duration distribution that can be re-scaled to produce variable sediment storage times by varying $T_{\text {cut }}$. To aid in model-data comparisons, it is useful to develop a prediction for how $T_{\text {cut }}$ may vary between river systems. Based on a separate set of meandering model runs with variable maximum lateral migration rates $(0.0005$ to 0.05 channel widths per year), we found that $T_{\text {cut }}$ is proportional to the inverse of the maximum lateral migration rate such that

$T_{\text {cut }}=c_{1} \times\left(\frac{w}{E_{\mathrm{L}, \max }}\right)$,

where $w$ is the channel width $(\mathrm{m}), E_{\mathrm{L}, \max }$ is the maximum lateral migration rate $\left(\mathrm{m} \mathrm{yr}^{-1}\right)$ and $c_{1}$ is an empirical constant equal to $13.6 \pm 3.3$ (Fig. 2a). Maximum lateral migration rates $\left(E_{\mathrm{L}, \max }\right)$ are used for this comparison because they are specified in the model runs; mean rates $\left(E_{\mathrm{L}}\right)$ are typically a factor of 3 lower.

Field compilations show that mean lateral migration rates are positively correlated with sediment fluxes $\left(Q_{\mathrm{s}}\right.$; Fig. 2;
Aalto et al., 2008; Grenfell et al., 2012; Constantine et al., 2014). This correlation may reflect the fact that in order for the river channel to migrate by one channel width, sufficient sediment must be supplied so that a deposit of equivalent volume is created. Along a meander bend, the volume of the sediment deposit produced after a river migrates one channel width should be proportional to the product of the bend wavelength $\left(\lambda_{\text {bend }}\right)$, channel depth $(h)$, and channel width $(w)$. In field data (e.g., Williams, 1986), both $\lambda_{\text {bend }}$ and $h$ are correlated with $w$ such that the deposit volume can be approximated as being proportional to $w^{3}$. In Fig. 2, the correlation between lateral migration rates and sediment fluxes (Constantine et al., 2014) is recast in terms of two timescales: the time required to migrate one channel width $\left(w / E_{\mathrm{L}}\right)$ and the time required to supply a proportional volume of sediment $\left(w^{3} / Q_{\mathrm{s}}\right)$. Taken all together, the correlations depicted in Fig. $2 \mathrm{a}-\mathrm{b}$ imply that relative $T_{\text {cut }}$ values can be determined for field systems through comparison of $w^{3} / Q_{\mathrm{s}}$. That is, natural rivers with higher $w^{3} / Q_{\mathrm{s}}$ appear to migrate more slowly and therefore store sediments for longer.

\subsection{Model for the number of storage events}

Following the generic theory presented in Sect. 2.1, the sediment transit time is equal to the sum of independent draws from the storage duration distribution with the number of independent draws being equal to the total number of storage events (Eq. 1). Thus, calculating transit time distributions (TTDs) from the storage duration distribution requires a model for the total number of storage events sediment undergoes during riverine transit.

Following previous approaches (e.g, Malmon et al., 2003; Lauer and Parker, 2008b; Pizzuto et al., 2014), we defined a characteristic length scale over which eroded sediment particles are transported before being re-deposited. While particles are transported variable distances (depending for example on particle size and current velocity), we made the simplifying assumption that the spread of the distribution of transport lengths is small relative to the mean transport length. We defined the characteristic transport length $\left(x_{\text {tran }}\right)$ by balancing the flux of sediment carried downstream with the lateral flux of sediment that results from channel migration. In this way, $x_{\text {tran }}$ represents the length of channel required to exchange the entire sediment flux with river deposits via lateral migration. This definition of $x_{\text {tran }}$ is comparable to previous studies (Malmon et al., 2003; Lauer and Parker, 2008b; Pizzuto et al., 2014) and was calculated with the equation

$x_{\text {tran }}=\frac{Q_{\mathrm{s}}}{E_{\mathrm{L}} \times h}$

where $Q_{\mathrm{s}}$ is the volumetric sediment flux $\left(\mathrm{m}^{3} \mathrm{yr}^{-1}\right), E_{\mathrm{L}}$ is the mean lateral migration rate $\left(\mathrm{m} \mathrm{yr}^{-1}\right)$, and $h$ is the channel depth $(\mathrm{m})$. The appropriate number of transport events $\left(n_{x}\right)$ can be determined by taking the nearest integer of the ratio of the total channel length $(L)$ to $x_{\operatorname{tran}}\left(n_{x}=\left\lfloor L / x_{\operatorname{tran}}\right\rceil\right)$. 

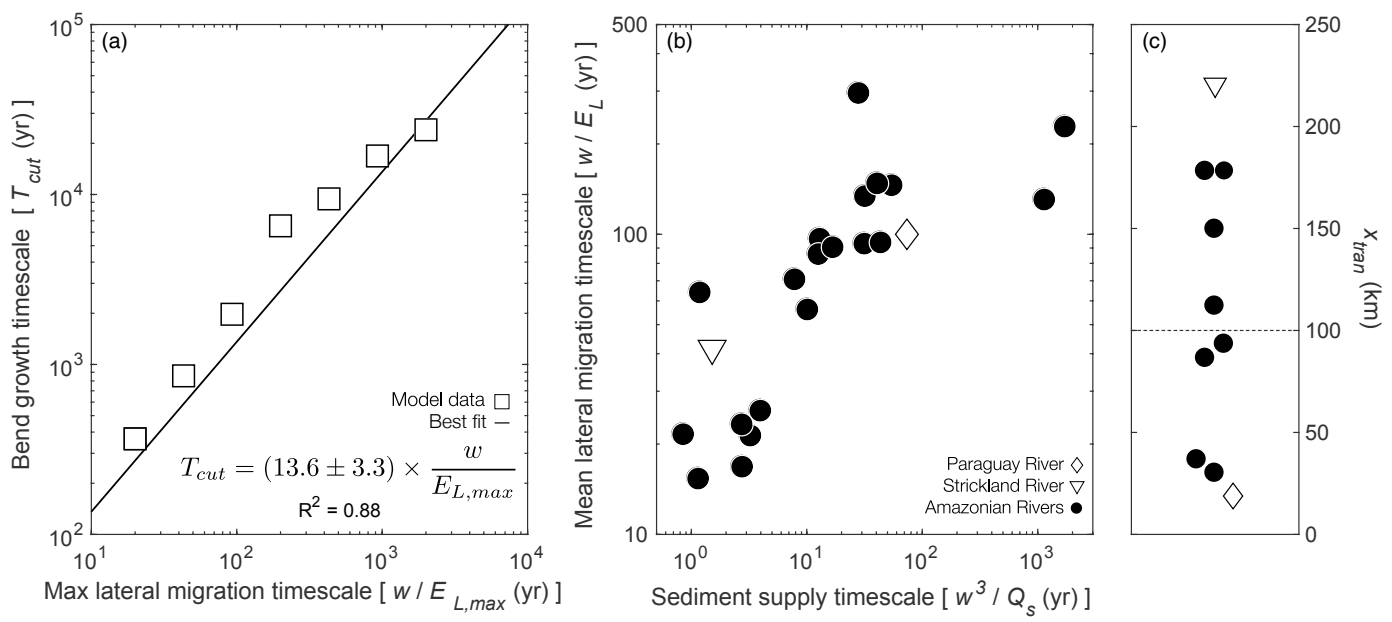

Figure 2. Sediment transport parameters in the model and field data. (a) The results of the numerical meandering model simulations that show that the meander bend growth timescale $\left(T_{\text {cut }}\right)$ is correlated with the time required for the channel to migrate one channel width at the maximum lateral migration rate $\left(E_{\mathrm{L}, \max }\right)$. (b) Field evidence (Aalto et al., 2008; Grenfell et al., 2012; Constantine et al., 2014) for a correlation between the mean time required to migrate one channel width $\left(w / E_{\mathrm{L}}\right)$ and the sediment supply timescale $\left(w^{3} / Q_{\mathrm{S}}\right)$. (c) Jitter plot of calculated $x_{\text {tran }}$ values (Eq. 4) for the field data shown in (b). Together, these panels show that $T_{\text {cut }}$ scales with the lateral migration rate, which, in field data, is correlated with suspended sediment fluxes (Constantine et al., 2014). The correlation between lateral migration rates and sediment fluxes results in minimal variation in the transport length scale and provides a proxy for $T_{\text {cut }}\left(\right.$ i.e., $\left.w^{3} / Q_{\mathrm{s}}\right)$ for rivers where lateral migration rates are unknown.

The sediment transit time distribution can then be determined by convolving the storage duration distribution with itself $n_{x}$ times (Eq. 1).

\subsubsection{Prediction of downstream changes}

By relating the number of transport events to a characteristic length scale (Eq. 4), our model predicts that sediment transit times will increase with increasing transport distance due to repeated storage in fluvial deposits. This relationship between channel length and transit time forms the basis of our comparison between model results and field data as it allows datasets without direct measurements of sediment transit times to be used. Correlations apparent in field data (Fig. 2b) imply that variations in $x_{\text {tran }}$ should be minimal between river systems such that variations in channel length are the dominant control on $n_{x}$ (see Eq. 4). Here, we set $x_{\text {tran }}$ equal to $100 \mathrm{~km}$, which is close to the mean $x_{\text {tran }}$ $(109 \pm 68 \mathrm{~km})$ calculated from the data compilation shown in Fig. $2 \mathrm{c}$ and agrees with a complementary, but independent, analysis by Pizzuto et al. (2017), which suggests that particles enter and exit storage reservoirs 10 times as they transit along a $1000 \mathrm{~km}$ long channel. However, we note that Pizzuto et al. (2017) also predict that the transport length scale increases with increasing river catchment area.

The predicted changes in sediment transit times with increasing transport length can be cast in terms of catchment area by taking advantage of the power-law relationship between channel length $(L ; \mathrm{km})$ and catchment area $\left(A ; \mathrm{km}^{2}\right.$; Hack, 1957). This relationship is useful because catchment areas have been reported for all field data within our compilation (see Sect. 2.5). We transformed modeled channel lengths using the equation

$L=1.4 \times A^{0.5}$.

The value of the exponent selected (0.5) reflects dimensional consistency and a compromise between small $\left(<2 \times 10^{5} \mathrm{~km}^{2}\right)$ and large $\left(>2 \times 10^{4} \mathrm{~km}^{2}\right)$ river catchments, which are characterized by larger (0.6) and smaller (0.47) exponents, respectively (Mueller, 1973). To model catchments with channel lengths shorter than $x_{\text {tran }}$, we assumed they have a mixture of POC with a zero age and POC aged by one transport event. The relative proportion of aged material is equal to the ratio of the channel length to $x_{\text {tran }}$.

\subsection{Linking sediment transit times to POC ages}

\subsubsection{End-member case with zero cycling}

To link our prediction of sediment TTDs to POC ages, we started by assuming that the age distribution of POC is equal to the sediment TTD. This can be conceptualized as a system where sediments from a source area contain an initial amount of POC with a zero age. The POC and sediments from the source area then transit through a river system with no subsequent POC oxidation or production. This simplified approach serves as a useful end-member case where POC increases in age as much as allowed by sediment storage. To contrast with this, Sect. 2.4.2 describes an approach that explicitly incorporates the effects of POC cycling into the prediction of POC age distributions. 
The radiocarbon content of riverine POC is often used as a tracer of the timescale of POC cycling. Typically, radiocarbon measurements are reported as the fraction modern (Fm), which is defined as

$\mathrm{Fm}=\left({\frac{1}{{ }^{14} \mathrm{C}}}_{{ }_{\text {sample } *}}\right) /\left(\frac{1}{14} \mathrm{C}_{{ }^{12} \mathrm{C}_{\text {modern }}}\right)$,

where the subscript sample* refers to the ratio of ${ }^{14} \mathrm{C}$ to ${ }^{12} \mathrm{C}$ in a sample normalized to a fixed ${ }^{13} \mathrm{C}$ to ${ }^{12} \mathrm{C}$ ratio $\left(\delta^{13} \mathrm{C}=-25 \%\right.$ o) and the subscript modern refers to the ${ }^{14} \mathrm{C}$ to ${ }^{12} \mathrm{C}$ ratio of a standard. Unlike calendar ages, Fm mixes linearly, making it appropriate for use in systems where POC is composed of a mixture of components with different ages.

Assuming conservative behavior of POC, the appropriate function to transform the sediment transit time distribution into a distribution of Fm values (following Eq. 2) is the radioactive decay equation

$\mathrm{Fm}=e^{-\lambda t}$

where $\lambda$ is the ${ }^{14} \mathrm{C}$ decay constant $\left(1.209 \times 10^{-4} \mathrm{yr}^{-1}\right)$. Here, we assumed that the ${ }^{14} \mathrm{C} /{ }^{12} \mathrm{C}$ ratio of the atmosphere is constant in time in order to simplify the model and focus on the role of sediment transport dynamics in setting the radiocarbon content of riverine POC.

\subsubsection{Modeling POC cycling in floodplains}

If POC is produced and/or consumed during floodplain storage, its age will not be equal to the age of the sediment deposit in which it occurs. If, for example, new POC is produced as older POC is consumed, then the radiocarbon content of bulk POC will increase and be shifted to younger ages relative to the sediment deposit. Production and consumption of POC during sediment storage is consistent with existing radiocarbon measurements from soil chronosequences. Importantly, soil chronosequence studies from environments where the parent material contains little to no petrogenic POC show a general decrease in the Fm of biospheric POC with deposit age (Torn et al., 1997; Lawrence et al., 2015). This relationship implies that, even with active POC cycling, sediment storage will affect the age distribution of riverine POC.

Including the effects of POC cycling in our modeling framework requires a description of the kinetics of $\mathrm{POC}$ production and consumption. We adopted a simple approach in order to demonstrate the general effects of POC cycling (based on Jenny et al., 1949). This model assumes that the time rate of change in the POC content of a sediment deposit depends on the balance between POC production and consumption. For simplicity, POC consumption is assumed to be first order with respect to POC concentration, which yields the equation

$\frac{\mathrm{d} C}{\mathrm{~d} t}=P-k(C)$ where $C$ is the POC concentration $\left(\mathrm{g} \mathrm{cm}^{-3}\right), P$ is the production rate $\left(\mathrm{g} \mathrm{cm}^{-3} \mathrm{yr}^{-1}\right)$, and $k$ is the consumption rate constant $\left(\mathrm{yr}^{-1}\right)$. This equation predicts that the concentration of POC within a sediment deposit evolves towards a steadystate concentration equal to $P / k$. The $e$-folding time of this evolution is equal to $1 / k$.

To incorporate radiocarbon (as Fm) into this model, it is necessary to write separate versions of Eq. (8) for ${ }^{12} \mathrm{C}$ and ${ }^{14} \mathrm{C}$. For ${ }^{14} \mathrm{C}$, an additional term is required to account for radioactive decay, which yields the equation

$\frac{\mathrm{d}^{14} \mathrm{C}}{\mathrm{d} t}={ }^{14} P-k\left({ }^{14} \mathrm{C}\right)-\lambda\left({ }^{14} \mathrm{C}\right)$.

When combined with Eq. (8), Eq. (9) predicts that the Fm of biospheric POC decreases with time to a steady-state value equal to $k /(\lambda+k)$. For a given steady-state concentration of POC, the time required for the system to reach steady state with respect to Fm scales negatively with the POC consumption rate constant (i.e., systems with more slowly cycling carbon require more time to reach a steady state).

Equations (8) and (9) can be integrated in order to generate equations that predict the concentration and Fm of POC as a function of time. These integrated equations can then be used to transform any age distribution into a distribution of POC concentrations and Fm (analogously to Eq. 2). Simply transforming the transit time distribution would imply that, in between transport events, POC sourced from the erosion of variably aged sediment deposits is not mixed together in the river channel, which is unlikely to be true. Instead, to simulate in-channel mixing, the initial concentration and Fm of POC deposited can be made to vary downstream based on the extent of aging during each transport event.

For the first transport event, the storage duration distribution is transformed with the integrated forms of Eqs. (8) and (9), where the initial POC concentrations are equal to zero. This accounts for the POC produced and consumed during the first storage event as sediment transits through a river system. When these upstream sediment deposits are eroded, they will transport a mixture of variably aged POC downstream until it is re-deposited. We assume that the initial concentration and Fm of POC incorporated into these downstream deposits is equal to the means of the concentration and Fm (weighted by concentration) of eroded deposits from the preceding storage event. These initial values are used to generate new functions from Eqs. (8) and (9) to transform the storage duration distribution for the next storage event. Note that the aggregate Fm values modeled in this manner are not strictly "ages" in any meaningful way but instead represent the Fm that results from a dynamic balance between POC production, consumption, and radioactive decay.

\subsubsection{Accounting for the chemical heterogeneity of POC}

Applying Eqs. (8) and (9) requires specifying values for the POC production rate and consumption rate constant. Natural 
POC is a compositionally heterogeneous material, and cannot be described by single values for these parameters due to differing rates of biological production and/or resistance to (bio)degradation. To account for this expected heterogeneity, Eqs. (8) and (9) can sum across multiple POC "pools" with differing production rates $(P)$ and consumption $(k)$ rate constants (Jørgensen, 1978; Berner, 1980; Boudreau and Ruddick, 1991). For POC concentrations, this can be written as

$$
\frac{\mathrm{dC}}{\mathrm{d} t}=\sum_{i=1}^{j} P_{i}-k_{i}\left(\mathrm{C}_{i}\right),
$$

where $i$ represents an individual POC pool and $j$ is the total number of POC pools. An analogous equation can be written for ${ }^{14} \mathrm{C}$ by adding the term for radioactive decay for each POC pool.

Applying Eq. (10) requires specifying the number of POC pools as well as their individual steady-state concentrations and consumption rate constants. A simple version of such a model involves two POC pools $(j=2)$ : "fast" cycling POC and "slow" cycling POC. The fast cycling POC pool has a higher steady-state concentration and a higher consumption rate constant relative to the slow cycling pool. As a result, POC concentrations are dominated by the fast pool, while Fm values are more sensitive to the slow cycling pool.

Using the sediment TTDs we developed, we calculated the bulk radiocarbon content of riverine POC using different parameter values of the two-pool POC cycling model. In all models, the consumption rate constant for the fast cycling POC pool was set equal to $0.01 \mathrm{yr}^{-1}$. Similarly, the production rates of fast POC were fixed to produce a steady-state concentration of fast POC equal to $0.1 \mathrm{~g} \mathrm{~cm}^{-3}$. As long as the rate constant for fast cycling POC is greater than $0.001 \mathrm{yr}^{-1}$, its value has little effect on the model results as this pool cycles rapidly enough to maintain a $\mathrm{Fm} \approx 1$. To produce POC with a low $\mathrm{Fm}$ value, we set the rate constant describing the slow cycling POC pool to either $2 \times 10^{-6}$ or $2 \times 10^{-5} \mathrm{yr}^{-1}$. Production rates of slow POC were varied such that the steady-state concentration of slow POC was between 5 and $80 \%$ of the total (fast + slow) steady-state POC concentration. While consistent with some available field data (e.g., Middelburg, 1989), these parameter values were largely selected in order to produce the range of biospheric Fm values observed in natural rivers (see Sect. 2.5 below).

\subsection{Field data compilation and analysis}

To benchmark our model results, we compiled field data on the radiocarbon content of riverine POC. As previously mentioned, the bulk radiocarbon content of riverine POC is strongly affected by the mixing of biospheric POC $(\mathrm{Fm} \leq 1)$ with petrogenic POC $(\mathrm{Fm}=0)$. Since our model predicts only the change in the radiocarbon content of biospheric POC, it is necessary that we correct for the proportion of petrogenic POC in field data. This is accomplished using a modified version of the Galy et al. (2008) two-component mixing model, which requires datasets with more than two measurements of Fm per site.

We identified 50 river systems with more than two measurements of the concentration and radiocarbon content of riverine POC (full reference list in Table 1). Following Galy et al. (2008), the bulk Fm measurement can be related to the proportions of petrogenic POC $\left(\mathrm{POC}_{\mathrm{p}}\right)$ and biospheric POC $\left(\mathrm{POC}_{b}\right)$ by the equation

$\mathrm{Fm}_{\text {bulk }} \times[\mathrm{POC}]_{\text {bulk }}=\left(\mathrm{Fm}_{b} \times[\mathrm{POC}]_{b}\right)+\left(\mathrm{Fm}_{\mathrm{p}} \times[\mathrm{POC}]_{\mathrm{p}}\right)$,

where $[\mathrm{POC}]$ is the concentration of POC in units of grams of $\mathrm{C}$ per gram of sediment. If it is assumed that petrogenic POC is present at a fixed concentration in sediments, then the relationship

$[\mathrm{POC}]_{\mathrm{p}}=[\mathrm{POC}]_{\mathrm{bulk}}-[\mathrm{POC}]_{b}$

can be substituted into Eq. (11). Since the Fm of petrogenic $\mathrm{C}$ is equal to zero, the assumptions stated above yield the hyperbolic equation:

$\mathrm{Fm}_{\text {bulk }}=\frac{\mathrm{Fm}_{b} \times\left([\mathrm{POC}]_{\mathrm{bulk}}-[\mathrm{POC}]_{\mathrm{p}}\right)}{[\mathrm{POC}]_{\mathrm{bulk}}}$.

All the data from each individual site in our compilation were fit with the nonlinear form of the mixing equation (Eq. 13) using the trust-region algorithm available in the MATLAB 2015a Curve Fitting Toolbox. Since Eq. (13) predicts a hyperbolic relationship between POC concentrations and Fm that is concave down, we screened all of the regression results in order to identify instances where a two-component mixing model was inconsistent with the data. Of the 50 river systems in the data compilation, 21 were consistent with the twocomponent mixing model (Eq. 13) and yielded an estimate of the Fm of bulk biospheric POC (results shown in Table 2). Of these 21 river systems, we excluded one (the Rhône River; biospheric $\mathrm{Fm}=1.41 \pm 0.15$ ) from further analysis due to its high Fm, which we attribute to anthropogenic contamination.

\section{Results}

\subsection{Meandering model predictions of storage durations}

Averaged across our model simulations, the probability distribution of storage durations shows a power-law decay in probability as the storage duration increases (Fig. 3a). We considered this to be a key feature of the meandering model results, and aimed to capture it in our statistical representation of the modeled age distributions. Without an upper bound, power-law distributions can have infinite moments and thus have limited value in describing the full range of behavior of natural systems. Since our model simulations show evidence for an upper bound (Fig. 3a) and natural river systems have a finite size and, in the absence of external forcing, 

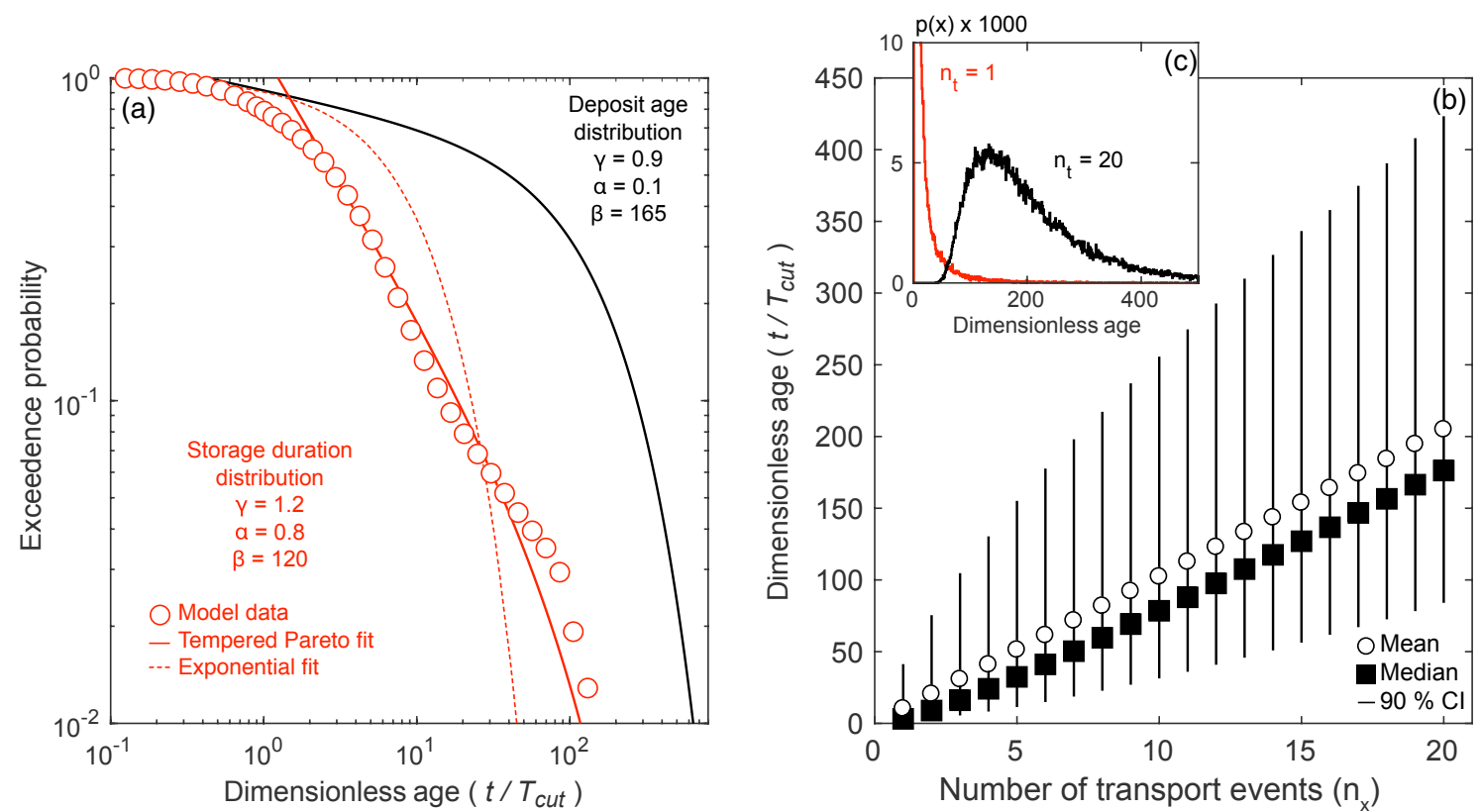

Figure 3. Dimensionless age distributions. (a) The survival function (complementary cumulative distribution function) of sediment storage durations (red points) derived from the meandering model. The sediment storage durations are normalized by a cutoff time ( $\left.T_{\text {cut }}\right)$ of 350 years based on explicit tracking of meander bend growth following the approach of Schwenk et al. (2015). The best fitting tempered-Pareto and exponential distributions are shown as solid and dashed red lines, respectively. Also shown is a tempered-Pareto fit to the distribution of deposit ages at the end of the model simulation (black line). (b-c) The change in the shape of the sediment transit time distribution (normalized by $T_{\text {cut }}$; Eq. 3) with increasing number of transport events. (b) The mean, median, and $90 \%$ confidence interval of the sediment transit time distributions for 1 to 20 transport events. (c) The probability density function of sediment transit time distributions for 1 and 20 transport events. Consistent with the central limit theorem, the shape of the sediment transit distribution varies with the number of transport events.

are expected to eventually recycle more or less all the sediment they store, we employed a tempered-Pareto distribution (Cartea and Del-Castillo-Negrete, 2007; Rosiński, 2007) to describe our model results. The tempered-Pareto distribution is characterized a power-law decay until some scale and it is exponentially tempered beyond this scale. Relative to the truncated Pareto distribution (Mantegna and Stanley, 1994), which simply has a fixed upper bound, the tempered-Pareto distribution is less restrictive as it allows the upper bound to also be an exponentially distributed stochastic quantity.

Using the approach outlined in Meerschaert et al. (2010), we fit the dimensionless storage duration distribution determined from the meandering model simulations to a tempered-Pareto distribution ( $p(t)$; Fig. 3a), which has a probability density function (pdf) given by

$p(t)=\gamma t^{-\alpha-1} \times e^{-t / \beta} \times(\alpha+t / \beta)$,

where $t$ is the storage duration, $\gamma$ is a scale parameter, $\alpha$ is a tail index, and $\beta$ is a tempering parameter. The $\gamma$ parameter relates to the lower bound of the probability distribution and thus sets the minimum storage time. The $\alpha$ parameter describes the power-law decay in the relationship between probability and storage duration. The $\beta$ parameter describes the storage duration at which power-law behavior ceases and the storage duration distribution begins to follow an exponential function. Our best-fit values of $\gamma, \alpha$, and $\beta$ are 1.2, 0.8 , and 120 . We used Eq. (14) with these values as the storage duration distribution in order to calculate the sediment TTDs used in all subsequent results (Eq. 1).

At steady state, the storage duration distribution can be uniquely related to the ages of sediment deposits remaining in storage after one transport event (Bolin and Rodhe, 1973; Bradley and Tucker, 2013). Specifically, Bradley and Tucker (2013) demonstrated that the pdf of deposit ages $\left(p_{\mathrm{A}}(\mathrm{t})\right)$ is proportional to the survivor function (or complementary cumulative distribution function) of storage durations $\left(S_{\mathrm{S}}(t)\right)$ :

$p_{\mathrm{A}}(t)=\tau \times S_{\mathrm{S}}(t)$,

where $\tau$ is a constant of proportionality that is equal to the ratio of the total sediment reservoir size to either the input or output fluxes. Given the relationship between density and survivor functions, Eqs. (14) and (15) make a prediction for the relationship between the tail indices of the deposit age $\left(\alpha_{\mathrm{d}}\right)$ and storage duration $\left(\alpha_{\mathrm{s}}\right)$ distributions. Specifically, $\alpha_{\mathrm{d}}$ $=1-\alpha_{\mathrm{S}}$ at steady state. Individually fitting the results of each of our five replicate simulations yields $\alpha_{\mathrm{S}}$ values that range from 0.8 to 1 . This range of $\alpha_{\mathrm{s}}$ values, which we assume represents the uncertainty of our estimate, predicts a range of $\alpha_{\mathrm{d}}$ 
Table 1. List of all rivers and their associated citations included in the radiocarbon compilation.

\begin{tabular}{|c|c|}
\hline River & Citation \\
\hline Alsea & Hatten et al. (2012) \\
\hline \multirow{2}{*}{ Amazon } & Bouchez et al. (2010) \\
\hline & Bouchez et al. (2014) \\
\hline Arctic Red & Hilton et al. (2015) \\
\hline \multirow[t]{2}{*}{ Atchafalaya } & Gordon and Goni (2003) \\
\hline & Rosenheim et al. (2013) \\
\hline Avon & Adams et al. (2015) \\
\hline Beni & Bouchez et al. (2010) \\
\hline Brahmaputra & Galy et al. (2007) \\
\hline Calder River & Adams et al. (2015) \\
\hline Changjiang (Yangtze) & Wang et al. (2012); Li et al. (2015) \\
\hline Chontabamba & Townsend-Small et al. (2007) \\
\hline Chorobamba & Townsend-Small et al. (2007) \\
\hline Conwy & Adams et al. (2015) \\
\hline Dee & Adams et al. (2015) \\
\hline Eel & Leithold et al. (2006) \\
\hline \multirow{2}{*}{ Erlenbach } & Smith et al. (2013) \\
\hline & Turowski et al. (2016) \\
\hline Esperanza & Townsend-Small et al. (2007) \\
\hline Fly & Alin et al. (2008) \\
\hline Fraser & Voss (2014) \\
\hline Ganges & Galy et al. (2007) \\
\hline Garin & Adams et al. (2015) \\
\hline Hodder & Adams et al. (2015) \\
\hline Huancabamba & Townsend-Small et al. (2007) \\
\hline Kosi & Galy et al. (2007) \\
\hline Kosñipata & Clark et al. (2013) \\
\hline Lanyan Hsi & Kao and Liu (1996) \\
\hline Liard & Hilton et al. (2015) \\
\hline Liwu & Hilton et al. (2010) \\
\hline Llamaquiz & Townsend-Small et al. (2007) \\
\hline Madeira & Bouchez et al. $(2010,2014)$ \\
\hline Meghna & Galy et al. (2007) \\
\hline Mekong & Martin et al. (2013) \\
\hline Mississippi & Rosenheim et al. (2013) \\
\hline Narayani & Galy et al. (2007) \\
\hline Navarro & Leithold et al. (2006) \\
\hline Noyo & Leithold et al. (2006) \\
\hline Peel & Hilton et al. (2015) \\
\hline Pozuzo & Townsend-Small et al. (2007) \\
\hline Rhône & Cathalot et al. (2013) \\
\hline Ribble & Adams et al. (2015) \\
\hline \multirow[t]{2}{*}{ Santa Clara } & Komada et al. (2004) \\
\hline & Masiello and Druffel (2001) \\
\hline Siuslaw & Leithold et al. (2006) \\
\hline Solimões & Bouchez et al. $(2010,2014)$ \\
\hline Strickland & Alin et al. (2008) \\
\hline Tokachi & Nagao et al. (2005) \\
\hline Umpqua & Goñi et al. (2013) \\
\hline Waiapu & Leithold et al. (2006) \\
\hline Waipaoa & Leithold et al. (2006) \\
\hline \multirow[t]{3}{*}{ Yellow (Huanghe) } & Wang et al. (2012) \\
\hline & Tao et al. (2015) \\
\hline & Hu et al. (2015) \\
\hline Zengjiang & Gao et al. (2007) \\
\hline
\end{tabular}

values that overlaps with our best-fit estimate of $\alpha_{\mathrm{d}}$ from fitting Eq. (14) to the deposit age distribution derived from fifty replicate model simulations $\left(\alpha_{d}=0.1\right.$; Fig. 3a). This consistency between the storage duration and deposit age distributions suggests that our model simulations were at steady state with respect to sediment storage statistics.

By using the tempered-Pareto distribution (Eq. 14) to represent the distribution of storage durations, we excluded storage durations less than the lower bound, which is related to the $\gamma$ parameter and approximately equal to one cutoff time. In our model simulations, the proportion of the age distribution with storage durations less than the lower bound is small (Fig. 3a), which implies that the lower bound imposed by the tempered-Pareto distribution may not significantly affect our modeled transit time distributions. Similarly, for modeling POC cycling, a fixed lower bound may be a reasonable approximation since soil chronosequence studies imply that the onset of significant organic carbon accumulation is lagged relative to the time of sediment deposition (Torn et al., 1997; Masiello et al., 2004; Lawrence et al., 2015). Consequently, the small proportion of young sediments not included in our model is not expected to participate significantly in organic carbon cycling.

\subsubsection{Non-dimensional model behavior}

To show the general model behavior, we started by comparing the dimensionless sediment TTDs generated using Eqs. (1) and (14) for 1 to 20 transport events (Fig. 3b). As expected, our calculations show that sediment ages increase with the number of transport events. They also show that the shape of the transit time distribution changes with increasing number of transport events (Fig. 3c). This change in shape is due to the central limit theorem, which states that sum of independent random variables tends towards a normal distribution even when drawn from a distribution that is not normal. The central limit theorem applies in this case because the tempered-Pareto distribution has finite moments due to the exponential tempering of the longest storage durations. However, as a semi-heavy-tailed distribution, sums of tempered-Pareto variables take longer to converge to a normal distribution relative to exponentially distributed variables. As a result, sediment TTDs skewed towards older ages are expected despite the mixing effects of multiple transport events (Fig. 3b, c).

The dimensionless sediment TTDs show a roughly linear increase in the mean transit time (MTT) with increasing number of transport events (Fig. 3b). Assuming that $x_{\text {tran }}$ is relatively constant, which is consistent with field data (Fig. 2c), the number of transport events should increase with the ratio of the square root of catchment area to $x_{\text {tran }}$ (Eq. 5; Hack, 1957). This metric for the relative number of transport events $\left(\sqrt{A} / x_{\text {tran }}\right)$ can be combined with our metric for relative $T_{\text {cut }}$ values ( $w^{3} / Q_{\mathrm{s}}$; Sect. 2.2.1) to produce a metric for 
Table 2. Physical characteristics and inferred biospheric Fm values for a subset of rivers in the radiocarbon compilation. The values of sediment fluxes are taken from the original studies and are based on either suspended sediment gauging or cosmogenic nuclide concentrations. We report the uncertainty on our estimate of biospheric Fm using Eq. (13) as 1 standard deviation $(\sigma)$.

\begin{tabular}{lrrrrll}
\hline River & $\begin{array}{r}\text { Sediment flux } \\
\left(\mathrm{Mt} \mathrm{yr}^{-1}\right)\end{array}$ & $\begin{array}{r}\text { Channel width } \\
(\mathrm{m})\end{array}$ & $\begin{array}{r}\text { Catchment area } \\
\left(\mathrm{km}^{2}\right)\end{array}$ & Fm bio & $\sigma$ & $\begin{array}{l}\text { Additional data } \\
\text { source }\end{array}$ \\
\hline Alsea & 0.07 & 65 & 1220 & 1.05 & 0.01 & USGS \\
Amazon & 785 & 4767 & 4618750 & 0.82 & 0.04 & HYBAM \\
Beni & 212 & 410 & 69980 & 0.94 & 0.14 & Wittmann et al. (2015) \\
Brahmaputra & 540 & 4052 & 583000 & 0.64 & 0.03 & \\
Changjiang & 472 & 2000 & 1810000 & 0.75 & 0.07 & Google Earth \\
Eel & 14.00 & 250 & 8063 & 0.83 & 0.17 & USGS \\
Erlenbach & 0.001 & 5 & 0.74 & 0.87 & 0.16 & Nitsche et al. (2012) \\
Fraser & 20 & 450 & 230000 & 0.91 & 0.03 & Google Earth \\
Ganges & 660 & 1910 & 935000 & 0.76 & 0.02 & \\
Kosi & 135 & 412 & 53610 & 0.88 & 0.03 & Google Earth \\
Kosñipata A & 0.06 & 10 & 50 & 0.93 & 0.12 & \\
Kosñipata B & 0.18 & 17 & 160 & 1.11 & 0.07 & \\
Lanyan Hsi & 2.90 & 320 & 980 & 1.10 & 0.15 & Google Earth \\
Liard & 46 & 850 & 275000 & 0.52 & 0.03 & Google Earth \\
Madeira & 433 & 1401 & 1420000 & 0.72 & 0.03 & Google Earth \\
Meghna & 0.24 & 2600 & 1600000 & 0.65 & 0.03 & Google Earth \\
Navarro & 0.56 & 59 & 816 & 1.02 & 0.11 & USGS \\
Peel & 21 & 470 & 70600 & 0.52 & 0.07 & Google Earth \\
Rhône & 31 & 460 & 99000 & 1.41 & 0.15 & Google Earth \\
Santa Clara & 6.84 & 298 & 4200 & 0.84 & 0.15 & USGS \\
Solimões & 569 & 5893 & 2147740 & 0.87 & 0.02 & HYBAM \\
Umpqua & 1.4 & 435 & 13000 & 0.95 & 0.02 & USGS \\
\hline
\end{tabular}

the relative transit time of sediments where

RelativeTransitTime $\propto n_{x} T_{\text {cut }} \propto \frac{\sqrt{A}}{x_{\text {tran }}} \frac{w^{3}}{Q_{\mathrm{s}}}$.

This simplified metric captures the expected effects of sediment supply (Constantine et al., 2014) and channel length (Malmon et al., 2003; Lauer and Parker, 2008b; Pizzuto et al., 2014) on the duration of sediment storage in river deposits and is useful for comparing systems where more direct measurements of sediment ages are unavailable. We note that field estimates of sediment fluxes are often imperfect (e.g., Kirchner et al., 2001). However, we expect that large differences in sediment fluxes between field sites, such as those in our data compilation (Table 2), will provide meaningful insights into differences in sediment storage using Eq. (16).

\subsection{Coupling sediment storage to POC cycling}

\subsubsection{Radiocarbon as a POC storage tracer}

The radiocarbon content of biospheric POC is a tracer of the lifetime of POC in surface environments, which reflects both the rate of POC cycling and the duration of time over which these reactions occur. For a sediment deposit with a single age, the bulk radiocarbon content (as Fm) is set by the POC production rate, the POC consumption rate constant, and the deposit age (Eq. 9). For river sediments, which are composed of a mixture of variably aged deposits (Fig. 3), it is expected that the relationship between the bulk Fm, POC cycling parameters, and storage time will depart significantly from the behavior expected for a single-age deposit (Eq. 9). The magnitude of the difference between the heterogeneous (sediment TTD) and homogeneous (single-age deposit) cases depends on the transit time distribution as well as the values of the POC consumption rate constants. The direction and magnitude of the offset is important to constrain as it underlies the quantitative interpretation of field data.

In analyzing the model predictions, we start by comparing the predicted relationships between the mean transit time (MTT) and bulk Fm for heterogeneous systems with a distribution of sediment transit times versus homogeneous systems with a single transit time. For this analysis, we re-scaled the dimensionless sediment TTDs shown in Fig. $3 \mathrm{~b}$ using $T_{\text {cut }}$ values selected such that the MTT for each distribution shape varied between $10^{3}$ and $10^{6}$ years. This approach is consistent with field estimates of MTTs, which range from $10^{3}$ to $5 \times 10^{5}$ years when measured using sediment budgeting (Blöthe and Korup, 2013) or radionuclide approaches (Dosseto et al., 2006; Granet et al., 2010; Wittmann et al., 2015, 2016; Li et al., 2016).

The exact difference in Fm between the heterogeneous and homogeneous cases depends on the MTT (Fig. 4a). When the 

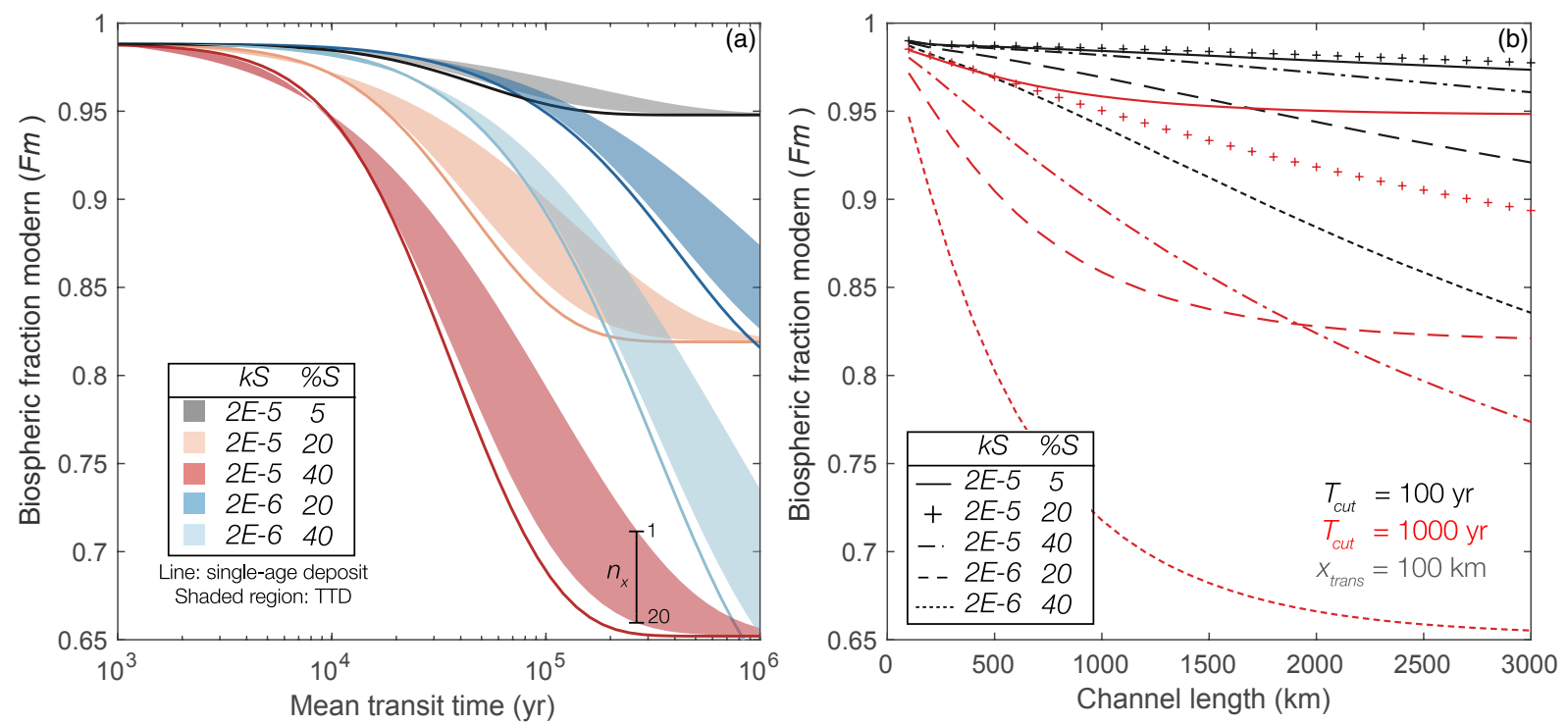

Figure 4. Model predictions of the radiocarbon content of POC. (a) Predicted relationships between sediment mean transit times (MTTs) and the Fm of biospheric POC for POC cycling models with variable proportions of slow POC $(\% S)$ and variable slow POC consumption rate constants $\left(\mathrm{kS} ; \mathrm{yr}^{-1}\right)$. Note that $\% S$ is equal to the proportion of slow POC at steady state. The Fm values shown as shaded areas were calculated using sediment transit time distributions (TTDs) with shapes set by between 1 and 20 transport events (Fig. 3) and MTTs between $10^{3}$ and $10^{6}$ years. The model results show that plausible sediment TTDs yield significantly different relationships between the MTT and Fm relative to predictions for systems with a single transit time (solid bold lines). While TTD shape is an important factor reflected in the vertical range of each shaded area, the model results suggest that large differences of OC cycling (different colors; see figure legend) are distinguishable in the relationships between the MTT and Fm. (b) Predicted downstream profiles of Fm for a fixed $x_{\text {tran }}(100 \mathrm{~km})$ but variable $T_{\text {cut }}$ (100 and 1000 years) and POC cycling parameters (different line styles; see figure legend). The model results suggest that observed downstream profiles are sensitive to both sediment storage timescales, which are controlled by $T_{\text {cut }}$, as well as OC cycling parameters.

MTT is long relative to the time it takes OC cycling to reach steady state, there is no difference between the Fm predicted by the heterogeneous and homogeneous models. However, when a significant portion of the sediment TTD consists of transit times less than the time required to reach steady state with respect to OC cycling, there are significant differences between the Fm predicted by the heterogeneous and homogeneous models. For the cases considered here, these differences can approach $0.1 \mathrm{Fm}$ units (Fig. 4a), which is 2 orders of magnitude greater than typical analytical uncertainties. Consequently, applying models based on homogeneous systems (e.g., Eqs. 8, 9, and 10) to radiocarbon measurements of riverine POC may yield parameter values that are off by large factors relative to their true values. In particular, applying homogeneous models to riverine POC is likely to yield apparent $\mathrm{OC}$ cycling rates that are fast relative to the "true" rates due to the significant proportion of sediments with short transit times.

While heterogeneous sediment TTDs lead to quantitatively distinct relationships between sediment MTTs and POC Fm values, the large differences in parameter values we selected allow the OC cycling models to be distinguished from one another despite the differences induced by variable TTD shapes (Fig. 4a). When there is only a very small fraction (i.e., $5 \%$ ) of slow OC, bulk Fm values remain close to
1 at all MTTs (Fig. 4a). Larger portions of slow OC result in more variable Fm values. For systems with identical values of POC consumption rate constants, increasing the portion of "slow" OC decreases the Fm observed at a given MTT (Fig. 4a).

In general, OC cycling models with lower POC consumption rate constants (i.e., slower OC cycling) have lower steady-state Fm values but take longer to reach steady state. As a result, for intermediate MTTs, the bulk Fm of riverine POC can have a higher value for systems with slower POC cycling rates relative to those with faster cycling rates (Fig. 4a). This counterintuitive result stems from mass balance constraints within the model, which require more slowly cycling compounds to be produced at slower rates if their concentrations are to remain a fraction of the total POC concentration. In other words, for the same MTT, more slowly cycling POC produced at a slower rate can yield a similar bulk Fm to more rapidly cycling POC produced at a faster rate (Fig. 4).

Results show that a single observation of the bulk Fm of riverine $\mathrm{POC}$ can yield a non-unique interpretation of the underlying POC cycling dynamics even if the sediment TTD is known independently (Fig. 4a). While this is also true when analyzing soil POC, the chronosequence approach (i.e., analyzing soils of variable, but independently known ages 
from the same site) can be used to better distinguish between different models. Our analysis highlights an analogous approach that can theoretically be applied to river systems where bulk Fm values can be compared within a given river system or between similar river systems with differing sediment transit times. In our results, OC cycling rates are distinguished by the shape of the relationship between MTT and bulk Fm (Fig. 4a). In principle, samples with variable MTTs can be collected from the same river system by analyzing a downstream profile of riverine POC over a length greater than the characteristic transport length scale (Eq. 4). However, spatial variations in $\mathrm{OC}$ cycling rates may complicate the interpretation of such analyses.

\subsection{The downstream profile of POC radiocarbon}

For fixed values of POC cycling rates, the bulk Fm of riverine biospheric POC depends on the MTT (Fig. 4a), which increases as the number of transport events increases (Fig. 3b). Thus, our model predicts that the bulk Fm of biospheric POC should decrease downstream. The exact shape of this decrease depends on the POC cycling rates as well as the relationships between channel length and sediment transit times set by the transport length scale $\left(x_{\text {tran }}\right)$, the number of transport events $\left(n_{x}\right)$, and the cutoff time $\left(T_{\text {cut }}\right)$.

For short channel lengths, all Fm-channel length relationships show Fm values near 1 (i.e., modern POC) due to limited storage (Fig. 4b). As channel length increases, each relationship tends towards the steady-state Fm that is set by the POC consumption rate constants (Fig. 4b). For each curve shown in Fig. 4b, the relative increase in channel length required to reach the steady-state Fm is set by $T_{\text {cut }}$ and $x_{\text {tran }}$. In other words, low Fm values require slow POC cycling rates, but these values can only be expressed with sufficient sediment storage, which increases with increasing channel length. This result illustrates that the downstream profile of the radiocarbon content of biospheric POC contains information regarding the interplay between sediment storage and OC cycling (Fig. 4b).

\subsubsection{Benchmark with natural systems}

The model results shown in Fig. 4a illustrate that increasing the proportion of slow cycling POC results in a decrease in Fm, whereas decreasing the consumption rate constant can increase Fm. With this in mind, we compared our compilation of field data to POC cycling models with fixed POC consumption rate constants (fast and slow rates of 0.01 and $2 \times 10^{-5} \mathrm{yr}^{-1}$, respectively) but variable proportions of slow POC (10, 33, and $80 \%)$. These OC cycling models are contrasted with an "inert" model (Sect. 2.4), where POC is assumed to have the same age distribution as the sediments. To produce a range of sediment MTTs, we consider simulations with $T_{\text {cut }}$ values of 350 and 1000 years.
All field data within our compilation fall within the region defined by our model predictions after taking into account the uncertainties in our estimates of biospheric Fm from field measurements (Fig. 5a). Rivers with small catchment areas tend to have high Fm values while rivers with larger catchments show a wider range of Fm (Fig. 5a). This behavior is predicted by our model wherein sufficient sediment storage is required to express differences in Fm values that result from variable POC cycling rates.

Our model predicts that variations in Fm for rivers with large catchment areas should depend on the rates of OC cycling, which we represent as the portion of slow POC. While it is difficult to independently quantify POC cycling rates at each of these sites, the observed meridional dependence of POC cycling implies that latitude can be used as a proxy for POC cycling rates (Carvalhais et al., 2014). Consistent with this, the larger catchments with high Fm values are all from low latitudes, while the larger catchments with low Fm values are from high latitudes (Fig. 5a).

Our model predictions of the relationship between catchment area and Fm are sensitive to both the portion of slow POC and $T_{\text {cut }}$ (Fig. 5a). In an attempt to control for the dependence of $T_{\text {cut }}$ on the relationships shown in Fig. 5a, we compare Fm values with the relative transit time metric developed in Sect. 3.1.1 (Eq. 16), which accounts for predicted differences in $T_{\text {cut }}$ using variations in $w^{3} / Q_{\mathrm{s}}$. Comparing the relative transit time of each river with the biospheric Fm yields a relationship consistent with our model predictions (Fig. 5b). As the relative transit time increases, biospheric Fm decreases as a result of radioactive decay during storage (Fig. 5b). As expected, the exact relationship between relative transit time and biospheric Fm is variable between sites due to the effects of OC cycling (Fig. 5b). By analyzing relative transit times (Fig. 5b), we find that the observed variations in the Fm of riverine biospheric POC are not solely due to variations in $\mathrm{OC}$ cycling but also arise from variations in sediment storage.

\section{Discussion}

\subsection{Behavior of biogeochemical cycles}

The storage of aged POC predicted by our model has implications for global biogeochemical cycles. Observations (Torn et al., 1997; Lawrence et al., 2015) and basic OC cycling models (e.g., Jenny et al., 1949) link the age of a soil or sediment deposit to its radiocarbon content and OC inventory. At the scale of river catchments, the amount of time available for OC accumulation and radioactive decay is set by the patterns of channel migration with time. These patterns lead to the preferential erosion of young deposits (Fig. 3a). Consequently, old deposits, which have accumulated more OC, are preferentially retained in floodplains (Fig. 3a). Thus, the dynamics of lateral channel migration imply that river deposits are a more sophisticated reservoir of OC than would be as- 

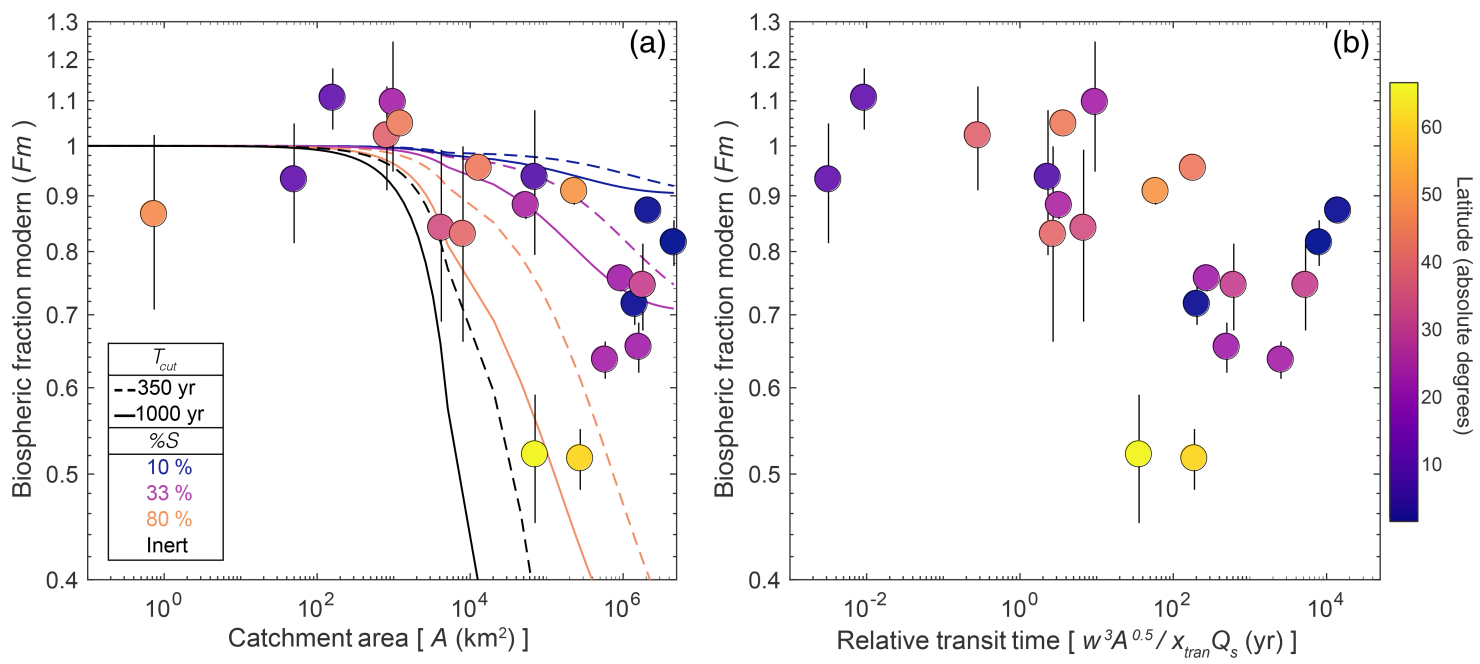

Figure 5. Field data compilation and comparison with model predictions. Field data are color coded based on their latitude as a proxy for POC cycling rates. (a) Model curves and field measurements of the relationship between catchment area and bulk biospheric Fm. Model curves are drawn for fixed POC consumption rate constants but variable steady-state proportions of "slow" cycling POC and $T_{\text {cut }}$ values (see legend). (b) Measured biospheric Fm values compared to our relative transit time metric (Eq. 16), which is based on Hack's law (Hack, 1957) and the scaling relationships shown in Figs. 2 and 3. The field data are consistent with the model predictions of aged POC in rivers with larger catchment areas and slower migration rates (inferred from variations in $w^{3} / Q_{\mathrm{s}}$ ) and thus longer sediment storage times. We note that in our compilation of rivers with measurements of biospheric Fm, catchment area and $w^{3} / Q_{\mathrm{s}}$ are correlated.

sumed by the null hypothesis of a well-mixed system due to their age structure. Similarly, river dynamics also influence the expression of these storage processes in geochemical tracers (e.g., Fm) by setting the relative proportions of variably aged river deposits sampled by fluvial erosion (Fig. 3).

Typically, the low radiocarbon content of riverine POC is assumed to result from the erosion of petrogenic OC from sedimentary rocks (Masiello and Druffel, 2001; Bouchez et al., 2010; Galy et al., 2008; Tao et al., 2015). Our results suggest that biospheric POC stored in river deposits can be another source of riverine POC that is depleted in radiocarbon. While our model predicts the bulk Fm of this stored OC reservoir, this value is associated with the time-averaged behavior of the river system and represents the average of all POC eroded by channel migration. On short timescales, the Fm of biospheric POC sampled by fluvial erosion may deviate from the time-averaged value predicted by our model depending on the ages of fluvial deposits being eroded. Potentially, such short-term variations in the Fm of the biospheric end-member may account for the fact many of the rivers in our compilation do not conform to two-component mixing between petrogenic and biospheric POC (Sect. 2.5).

Many previous studies of the terrestrial $\mathrm{OC}$ cycle have focused on the transport of terrestrial $\mathrm{OC}$ to marine depocenters, where it can be buried and stored over geologic timescales (Galy et al., 2015; Hilton, 2016). While this is undoubtedly an important process, our calculations suggest that sediment storage times in river deposits may approach geologic timescales (e.g., up to $10^{6}$ years; see also Pizzuto et al., 2017) and thus may play an important role in buffering changes in atmospheric $\mathrm{CO}_{2}$ and $\mathrm{O}_{2}$ concentrations. Moreover, the fluvial processes that dictate sediment storage timescales will also influence how terrestrial OC is transferred to marine basins. As a result, linkages between tectonic/climatic forcings and OC burial fluxes should include the mechanics of the reservoirs associated with terrestrial sediment-routing systems.

Presently, our model only accounts for lateral movements of a meandering river with time. In natural river systems, channel pattern (e.g., Eaton et al., 2010) and elevation changes driven by overbank deposition, subsidence, and aggradation may also influence the age structure of riverine POC. Since most overbank deposition is focused near the active channel (Pizzuto, 1987; Marriott, 1992; Aalto et al., 2008), the spatiotemporal pattern of lateral channel migration likely approximates the storage durations associated with these deposits. Overbank deposition distal to the channel coupled with subsidence can lead to the burial of sediment deposits below the scour depth of the migrating channel. By selectively removing the oldest deposits, this additional sediment (and POC) sink can truncate the distribution of sediment ages. Assuming a constant floodplain elevation, the time to bury a deposit beneath the scour depth can be approximated as the ratio of the channel depth to the subsidence rate. As long as this burial timescale is long relative to the upper bound of the storage duration distribution $(\beta$; Eq. 14), subsidence will play a subordinate role in setting the age distributions of riverine sediments and POC. This approach of comparing the timescales associated with lateral migration and sediment burial can be used to evaluate 

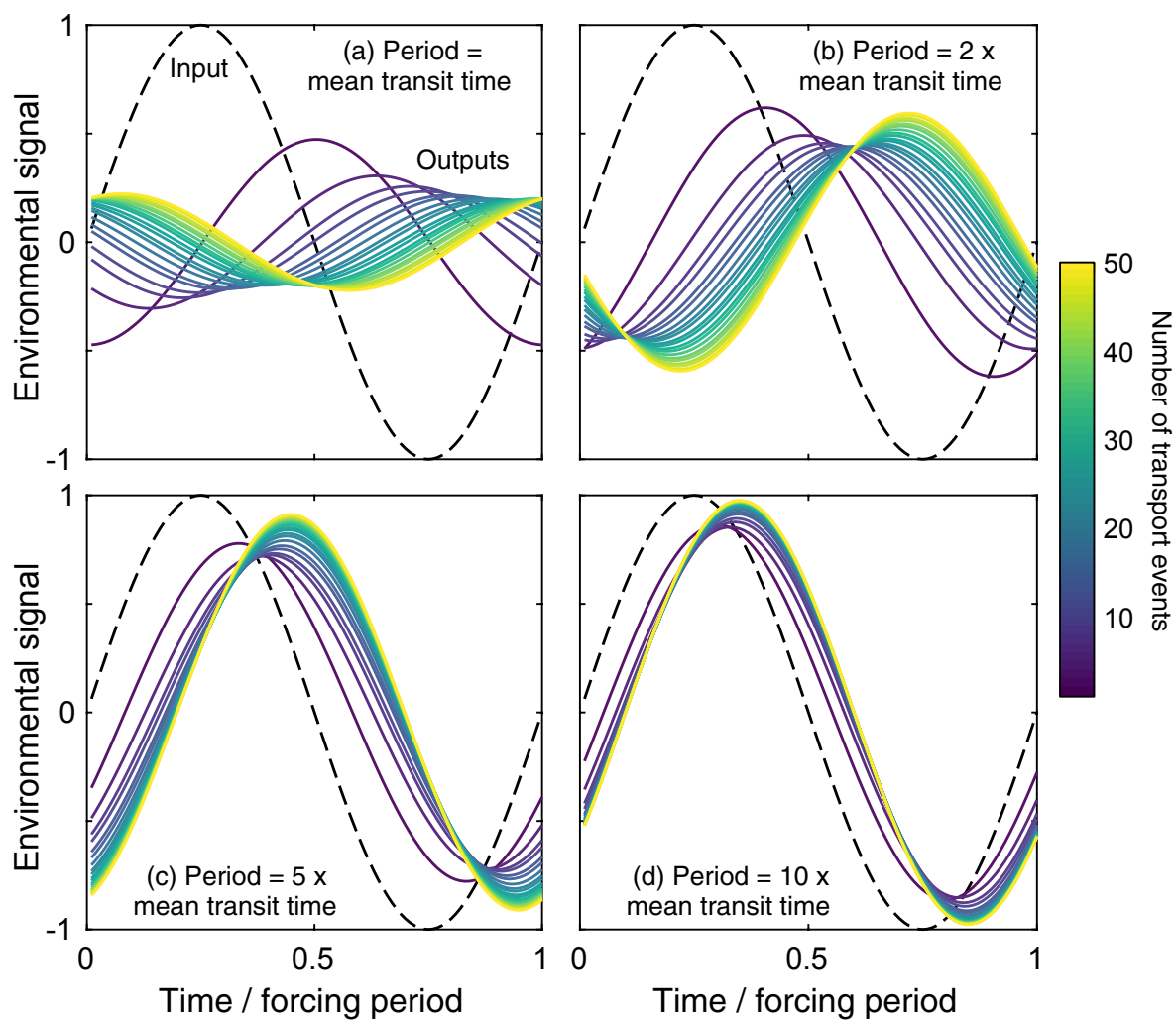

Figure 6. Effect of floodplain storage on environmental signals recorded by organic biomarkers. This figure shows the effect of convolving our sediment transit time distributions with a sine wave where the period of the sinusoidal input is equal to the mean transit time (a), twice the mean transit time (b), 5 times the mean transit time (c), and 10 times the mean transit time (d). The amplitude and phase of the sinusoidal input is shown as the black dashed lines. The colored lines refer to the output signal with the color reflecting the number of transport events (see color bar), which sets the shape of the transit time distribution. The model results suggest that climate signals recorded in terrestrial biomarkers will be significantly modulated if their period is short relative to the mean sediment transit time.

whether the model presented here is appropriate for a particular field system.

Altogether, the results of this study imply that the controls on the terrestrial OC cycle are not limited to the factors that affect rates of primary productivity and respiration but also include the dynamics of terrestrial sedimentary systems (see also Stallard, 1998; Galy et al., 2015; Hilton, 2016). Sediment transport processes dictate the time and space scales over which OC cycling occurs, warranting their explicit consideration in models of global biogeochemical cycles. Since the terrestrial biosphere, in turn, influences the behavior of fluvial systems (Tal and Paola, 2007; Gibling and Davies, 2012), there is scope for feedbacks between biogeochemistry, sediment transport processes, and the architecture of fluvial processes to have changed over Earth's history (Algeo and Scheckler, 1998; Gibling and Davies, 2012).

\subsection{Interpretation of time-varying environmental signals}

In addition to affecting the behavior of biogeochemical cycles, our predicted age distributions also have implications for how we interpret environmental changes preserved in sedimentary archives. For example, compound-specific isotopic analyses of terrestrial biomarkers are widely employed as proxies for environmental conditions (Eglinton and Eglinton, 2008). In systems where these compounds are delivered to a basin via an alluvial river system, they are likely to inherit some age structure as a result of sediment storage. This mixing of variably aged biomarkers will act as a signal filter and modify the sedimentary expression of environmental changes preserved in the isotopic composition of these compounds (Douglas et al., 2014). While such "shredding" of environmental signals has been extensively considered for sediments (Jerolmack and Paola, 2010; Ganti et al., 2014; Pizzuto et al., 2017), here we extended this type of analysis to organic biomarkers.

In Fig. 6, we show the effects filtering periodic signals of varying frequency with our sediment transit time distributions. Applied to biomarkers, these results show how an environmental signal recorded in the upstream portion of a catchment will be modified as a result of transient storage during transport from source to sink. While the extent of amplitude damping and phase lag at different frequencies is a 
generic outcome of signal filtering (Fig. 6), our model framework links these effects to physical properties of river systems (e.g., lateral migration rates, sediment fluxes, and channel length). For high-frequency signals, the relatively long transit time of biomarkers produced in the upstream portion of a river system creates a large phase lag between the original environmental signal and its sedimentary record (Fig. 6). Assuming these upland-sourced biomarkers are mixed with a more distal floodplain source that records environmental signals approximately in phase, the large phase lag between the two biomarker pools will cause destructive interference in the sedimentary expression of the environmental signal.

Based on our simplified analysis, we expect that knowledge of both the sediment transit time and POC age distributions may aid in the interpretation of proxy systems affected by fluvial averaging. We acknowledge that the application of our model framework will likely require the explicit modeling of the production and consumption of organic biomarkers during fluvial transit (Galy et al., 2011; Ponton et al., 2014) and site-specific information about sediment storage timescales. However, by identifying some of the potential controls on sediment transit times distributions, our study may be useful in terms of site selection for paleoclimate studies. Conversely, if the magnitude of the expected environmental signal were known independently, then its expression within a biomarker record could be used to infer properties of POC age distribution, as is done for water transit through catchment systems (e.g., McGuire and McDonnell, 2006; Kirchner, 2016). While this general approach was attempted by Douglas et al. (2014) using time series of terrestrial biomarkers in lake sediments, they assumed an arbitrary shape for the distribution of POC ages (a bimodal Gaussian distribution). Consequently, our modeling approach can be used to improve such efforts by providing a framework for generating more mechanistic POC age distributions.

\section{Conclusions}

Using simplified models that capture the physical processes associated with sediment storage for meandering rivers, we found that sediment transit time distributions exhibit a power-law decay, though geometric constraints temper or limit the distribution in our model simulations. Coupling our model for sediment transit time distributions to a simple model of OC cycling yields a full model for the radiocarbon content of riverine POC that can help interpret field observations. We find that riverine sediment storage is a major aspect of biogeochemical cycling that introduces a time continuum that runs from annual to potentially million-year timescales. A basic inference from the results of this study is that biomarkers will exhibit a delay and/or mixed signal that convolves both the forcing and the storage. Though complicating the interpretation of sedimentary records, which will incorporate a mixture of variably aged $\mathrm{POC}$, this river- floodplain exchange presents an opportunity to understand the timescales over which $\mathrm{CO}_{2}$ is stored as organic matter in surface deposits, which has important implications for understanding global environmental change.

Data availability. The raw data utilized in the study were compiled from previously published works and are available in the cited papers. In Table 2, we provide results derived from the data compilation. A working example of our sediment and carbon storage model is included as MATLAB script in the Supplement.

\section{The Supplement related to this article is available online at https://doi.org/10.5194/esurf-5-711-2017-supplement.}

Competing interests. The authors declare that they have no conflict of interest.

Acknowledgements. All authors thank James Pizzuto and one anonymous reviewer for providing helpful comments that greatly improved the overall quality of the paper. Mark A. Torres acknowledges support from a Caltech Texaco postdoctoral research fellowship and the California Alliance for the Graduate and Professoriate. Ajay B. Limaye acknowledges support from National Center for Earth-surface Dynamics 2 (NCED2) Synthesis Postdoctoral Program. Vamsi Ganti acknowledges support from the Imperial College London's Junior Research Fellowship. This work was supported by an award from the National Science Foundation to Michael P. Lamb (EAR 1427177) and the Caltech Discovery Fund. All authors acknowledge the participants of the GE126 course at Caltech (co-taught by Woodward W. Fischer, Michael P. Lamb, and A. Joshua West) for providing some of the early ideas that led to this work. Helpful criticism of a draft version of this paper was supplied by Joel Schiengross.

Edited by: Yves Godderis

Reviewed by: Jim Pizzuto and one anonymous referee

\section{References}

Aalto, R., Lauer, J. W., and Dietrich, W. E.: Spatial and temporal dynamics of sediment accumulation and exchange along Strickland River floodplains (Papua New Guinea) over decadal-to-centennial timescales, J. Geophys. Res., 113, F01S04, https://doi.org/10.1029/2006JF000627, 2008.

Adams, J. L., Tipping, E., Bryant, C. L., Helliwell, R. C., Toberman, H., and Quinton, J.: Aged riverine particulate organic carbon in four UK catchments, Sci. Total Environ., 536, 648-654, https://doi.org/10.1016/j.scitotenv.2015.06.141, 2015.

Algeo, T. and Scheckler, S.: Terrestrial-marine teleconnections in the Devonian: links between the evolution of land plants, weathering processes, and marine anoxic events, Philos. T. R. Soc. B, 353, 113-130, 1998. 
Alin, S. R., Aalto, R., Goni, M. A., Richey, J. E., and Dietrich, W. E.: Biogeochemical characterization of carbon sources in the Strickland and Fly rivers, Papua New Guinea, J. Geophys. Res.Earth, 113, 1-21, https://doi.org/10.1029/2006JF000625, 2008.

Berner, R. A.: A rate model for organic matter decomposition during bacterial sulfate reduction in marine sediments, in: Colloq. Int. CNRS, 293, 35-44, 1980.

Berner, R. A.: Biogeochemical cycles of carbon and sulfur and their effect on atmospheric oxygen over phanerozoic time, Palaeogeogr. Palaeocl., 75, 97-122, https://doi.org/10.1016/09218181(89)90018-0, 1989.

Bird, M., Lloyd, J., and Farquhar, G.: Terrestrial carbon storage during the LGM, Nature, 371, 566, https://doi.org/10.1038/371566a0, 1994.

Black, E., Renshaw, C. E., Magilligan, F. J., Kaste, J. M., Dade, W. B., and Landis, J. D.: Determining lateral migration rates of meandering rivers using fallout radionuclides, Geomorphology, 123, 364-369, https://doi.org/10.1016/j.geomorph.2010.08.004, 2010.

Blair, N. E. and Aller, R. C.: The fate of terrestrial organic carbon in the marine environment, Annu. Rev. Mar. Sci., 4, 401-423, https://doi.org/10.1146/annurev-marine-120709-142717, 2012.

Blöthe, J. H. and Korup, O.: Millennial lag times in the Himalayan sediment routing system, Earth Planet. Sc. Lett., 382, 38-46, https://doi.org/10.1016/j.epsl.2013.08.044, 2013.

Bolin, B. and Rodhe, H.: A note on the concepts of age distribution and transit time in natural reservoirs, Tellus A, 1, 58-62, https://doi.org/10.3402/tellusa.v25i1.9644, 1973.

Bouchez, J., Beyssac, O., and Galy, V.: Oxidation of petrogenic organic carbon in the Amazon floodplain as a source of atmospheric CO2, Geology, 38, 255-258, https://doi.org/10.1130/G30608.1, 2010.

Bouchez, J., Galy, V., Hilton, R. G., Gaillardet, J., MoreiraTurcq, P., Pérez, M. A., France-Lanord, C., and Maurice, L.: Source, transport and fluxes of Amazon River particulate organic carbon: Insights from river sediment depth-profiles, Geochim. Cosmochim. Ac., 133, 280-298, https://doi.org/10.1016/j.gca.2014.02.032, 2014

Boudreau, B. P. and Ruddick, B. R.: On a reactive continuum representation of organic matter diagenesis, American Journal of Science, https://doi.org/10.2475/ajs.291.5.507, 1991.

Bradley, D. N. and Tucker, G. E.: The storage time, age, and erosion hazard of laterally accreted sediment on the floodplain of a simulated meandering river, J. Geophys. Res.-Earth, 118, 1308-1319, https://doi.org/10.1002/jgrf.20083, 2013.

Cartea, A. and Del-Castillo-Negrete, D.: Fluid limit of the continuous-time random walk with general Levy jump distribution functions, Phys. Rev. E, 76, 1-8, https://doi.org/10.1103/PhysRevE.76.041105, 2007.

Carvalhais, N., Forkel, M., Khomik, M., Bellarby, J., Jung, M., Migliavacca, M., Mingquan, M., Saatchi, S., Santoro, M., Thurner, M., Weber, U., Ahrens, B., Beer, C., Cescatti, A., Randerson, J. T., and Reichstein, M.: Global covariation of carbon turnover times with climate in terrestrial ecosystems, Nature, 514, 213-217, https://doi.org/10.1038/nature13731, 2014.

Cathalot, C., Rabouille, C., Tisnérat-Laborde, N., Toussaint, F., Kerhervé, P., Buscail, R., Loftis, K., Sun, M. Y., Tronczynski, J., Azoury, S., Lansard, B., Treignier, C., Pastor, L., and Tesi, T.: The fate of river organic carbon in coastal areas: A study in the Rhone River delta using multiple isotopic $(\delta 13 \mathrm{C}, \delta 14 \mathrm{C})$ and organic tracers, Geochim. Cosmochim. Ac., 118, 33-55, https://doi.org/10.1016/j.gca.2013.05.001, 2013.

Clark, K. E., Hilton, R. G., West, A. J., Malhi, Y., Gröcke, D. R., Bryant, C. L., Ascough, P. L., Robles Caceres, A., and New, M.: New views on "old" carbon in the Amazon River: Insight from the source of organic carbon eroded from the Peruvian Andes, Geochem. Geophy. Geosy., 14, 1644-1659, https://doi.org/10.1002/ggge.20122, 2013.

Constantine, J. A., Dunne, T., Ahmed, J., Legleiter, C., and Eli, D.: Sediment supply as a driver of river evolution in the Amazon Basin, Nat. Geosci., 7, 899-903, https://doi.org/10.1038/NGEO2282, 2014.

Dosseto, A., Bourdon, B., Gaillardet, J., Allegre, C., and Filizola, N.: Time scale and conditions of weathering under tropical climate: Study of the Amazon basin with U-series, Geochim. Cosmochim. Ac., 70, 71-89, https://doi.org/10.1016/j.gca.2005.06.033, 2006.

Douglas, P. M. J., Pagani, M., Eglinton, T. I., Brenner, M., Hodell, D. A., Curtis, J. H., Ma, K. F., and Breckenridge, A.: Pre-aged plant waxes in tropical lake sediments and their influence on the chronology of molecular paleoclimate proxy records, Geochim. Cosmochim. Ac., 141, 346-364, https://doi.org/10.1016/j.gca.2014.06.030, 2014.

Dunne, T. and Aalto, R. E.: Large River Floodplains, 9, Elsevier, https://doi.org/10.1016/B978-0-12-374739-6.00258-X, 2013.

Eaton, B. C., Millar, R. G., and Davidson, S.: Channel patterns: Braided, anabranching, and single-thread, Geomorphology, 120, 353-364, https://doi.org/10.1016/j.geomorph.2010.04.010, 2010.

Eglinton, T. I. and Eglinton, G.: Molecular proxies for paleoclimatology, Earth Planet. Sc. Lett., 275, 1-16, https://doi.org/10.1016/j.epsl.2008.07.012, 2008.

Feng, X., Benitez-Nelson, B. C., Montluçon, D. B., Prahl, F. G., McNichol, A. P., Xu, L., Repeta, D. J., and Eglinton, T. I.: 14C and $13 \mathrm{C}$ characteristics of higher plant biomarkers in Washington margin surface sediments, Geochim. Cosmochim. Ac., 105, 1430, https://doi.org/10.1016/j.gca.2012.11.034, 2013.

Fischlin, A., Midgley, G., Price, J., Leemans, R., Gopal, B., Turley, C., Rounsevell, M., Dube, O., Tarazona, J., and Velichko, A.: Ecosystems, their properties, goods and services, in: Climate Change 2007: Impacts, Adaptation and Vulnerability, Contribution of Working Group II to the Fourth Assessment Report of the Intergovernmental Panel of Climate Change, vol. 48, chap. 4, 211-272, Cambridge University Press, available at: http://www.gtp89.dial.pipex.com/04.pdf (last access: 5 October 2016), 2007.

France-Lanord, C. and Derry, L. A.: Organic carbon burial forcing of the carbon cycle from Himalayan erosion, Nature, 390, 65-67, https://doi.org/10.1038/36324, 1997.

Frascati, A. and Lanzoni, S.: Morphodynamic regime and long-term evolution of meandering rivers, J. Geophys. Res.-Earth, 114, 112, https://doi.org/10.1029/2008JF001101, 2009.

Galy, V. and Eglinton, T.: Protracted storage of biospheric carbon in the Ganges-Brahmaputra basin, Nat. Geosci., 4, 843-847, https://doi.org/10.1038/ngeo1293, 2011.

Galy, V., France-Lanord, C., Beyssac, O., Faure, P., Kudrass, H., and Palhol, F.: Efficient organic carbon burial in the Bengal fan 
sustained by the Himalayan erosional system, Nature, 450, 40710, https://doi.org/10.1038/nature06273, 2007.

Galy, V., Beyssac, O., France-Lanord, C., and Eglinton, T.: Recycling of graphite during Himalayan erosion: a geological stabilization of carbon in the crust, Science, 322, 943-945, https://doi.org/10.1126/science.1161408, 2008.

Galy, V., Eglinton, T., France-Lanord, C., and Sylva, S.: The provenance of vegetation and environmental signatures encoded in vascular plant biomarkers carried by the GangesBrahmaputra rivers, Earth Planet. Sc. Lett., 304, 1-12, https://doi.org/10.1016/j.epsl.2011.02.003, 2011.

Galy, V., Peucker-Ehrenbrink, B., and Eglinton, T.: Global carbon export from the terrestrial biosphere controlled by erosion, Nature, 521, 204-207, https://doi.org/10.1038/nature14400, 2015.

Ganti, V., Straub, K. M., Foufoula-Georgiou, E., and Paola, C.: Space-time dynamics of depositional systems: Experimental evidence and theoretical modeling of heavytailed statistics, J. Geophys. Res.-Earth, 116, 1-17, https://doi.org/10.1029/2010JF001893, 2011.

Ganti, V., Lamb, M. P., and McElroy, B.: Quantitative bounds on morphodynamics and implications for reading the sedimentary record, Nat. Commun., 5, 1-7, https://doi.org/10.1038/ncomms4298, 2014.

Gao, Q., Tao, Z., Guanrong, Y., Ding, J., Liu, Z., and Liu, K.: Elemental and isotopic signatures of particulate organic carbon in the Zengjiang River, southern China, Hydrol. Process., 21, 13181327, https://doi.org/10.1002/hyp.6358, 2007.

Gibling, M. R. and Davies, N. S.: Palaeozoic landscapes shaped by plant evolution, Nat. Geosci., 5, 99-105, https://doi.org/10.1038/ngeo1376, 2012.

Goñi, M. A., Hatten, J. A., Wheatcroft, R. A., and Borgeld, J. C.: Particulate organic matter export by two contrasting small mountainous rivers from the Pacific Northwest, U.S.A., J. Geophys. Res.-Biogeo., 118, 112-134, https://doi.org/10.1002/jgrg.20024, 2013.

Gordon, E. S. and Goni, M. A.: Sources and distribution of terrigenous organic matter delivered by the Atchafalaya River to sediments in the northern Gulf of Mexico, Geochim. Cosmochim. Ac., 67, 2359-2375, https://doi.org/10.1016/S00167037(02)01412-6, 2003.

Granet, M., Chabaux, F., Stille, P., Dosseto, A., France-Lanord, C., and Blaes, E.: U-series disequilibria in suspended river sediments and implication for sediment transfer time in alluvial plains: The case of the Himalayan rivers, Geochim. Cosmochim. Ac., 74, 2851-2865, https://doi.org/10.1016/j.gca.2010.02.016, 2010.

Grenfell, M., Aalto, R., and Nicholas, A.: Chute channel dynamics in large, sand-bed meandering rivers, Earth Surf. Proc. Land., 37, 315-331, https://doi.org/10.1002/esp.2257, 2012.

Hack, J.: Studies of longitudinal stream profiles in Virginia and Maryland, USGS Professional Paper 249, p. 97, 1957.

Hatten, J. A., Goñi, M. A., and Wheatcroft, R. A.: Chemical characteristics of particulate organic matter from a small, mountainous river system in the Oregon Coast Range, USA, Biogeochemistry, 107, 43-66, https://doi.org/10.1007/s10533-010-9529-z, 2012.

Hickin, E. J. and Nanson, G. C.: The character of channel migration on the Beatton River, Northeast British Columbia, Canada, B. Geol. Soc. Am., 86, 487-494, https://doi.org/10.1130/00167606(1975)86<487:TCOCMO>2.0.CO;2, 1975.
Hilton, R. G.: Climate regulates the erosional carbon export from the terrestrial biosphere, Geomorphology, 277, 118-132, https://doi.org/10.1016/j.geomorph.2016.03.028, 2016.

Hilton, R. G., Galy, A., Hovius, N., Horng, M.-J., and Chen, H.: The isotopic composition of particulate organic carbon in mountain rivers of Taiwan, Geochim. Cosmochim. Ac., 74, 3164-3181, https://doi.org/10.1016/j.gca.2010.03.004, 2010.

Hilton, R. G., Galy, V., Gaillardet, J., Dellinger, M., Bryant, C., O'Regan, M., Gröcke, D. R., Coxall, H., Bouchez, J., and Calmels, D.: Erosion of organic carbon in the Arctic as a geological carbon dioxide sink, Nature, 524, 84-87, https://doi.org/10.1038/nature14653, 2015.

Hooke, J. M.: River channel adjustment to meander cutoffs on the River Bollin and River Dane, northwest England, Geomorphology, 14, 235-253, https://doi.org/10.1016/0169-555X(95)00110Q, 1995.

Howard, A. D. and Knutson, T. R.: Sufficient conditions for river meandering: A simulation approach, Water Resour. Res., https://doi.org/10.1029/WR020i011p01659, 1984.

Hu, B., Li, J., Bi, N., Wang, H., Wei, H., Zhao, J., Xie, L., Zou, L., Cui, R., Li, S., Liu, M., and Li, G.: Effect of humancontrolled hydrological regime on the source, transport, and flux of particulate organic carbon from the lower Huanghe (Yellow River), Earth Surf. Proc. Land., 1042, 1029-1042, https://doi.org/10.1002/esp.3702, 2015.

Jenny, H., Gessel, S. P., and Bingham, F. T.: Comparative study of decomposition rates of organic matter in temperate and tropical regions, Soil Sci., 68, 419-432, 1949.

Jerolmack, D. J. and Paola, C.: Shredding of environmental signals by sediment transport, Geophys. Res. Lett., 37, 1-5, https://doi.org/10.1029/2010GL044638, 2010.

Jørgensen, B.: A comparison of methods for the quantification of bacterial sulfate reduction in coastal marine sediments: I. Measurement with radiotracer techniques, Geomicrobiol. J., 1, 1127, 1978.

Kao, S.-J. and Liu, K.-K.: Particulate organic carbon export from a subtropical mountainous river (Lanyang Hsi) in Taiwan, Limnol. Oceanogr., 41, 1749-1757, https://doi.org/10.4319/lo.1996.41.8.1749, 1996.

Katsev, S. and Crowe, S. A.: Organic carbon burial efficiencies in sediments: The power law of mineralization revisited, Geology, 43, 607-610, https://doi.org/10.1130/G36626.1, 2015.

Keeling, C. D.: The Concentration and Isotopic Abundances of Carbon Dioxide in the Atmosphere, Tellus, 12, 200-203, https://doi.org/10.1111/j.2153-3490.1960.tb01300.x, 1960.

Keeling, R. F. and Shertz, S. R.: Seasonal and interannual variations in atmospheric oxygen and implications for the global carbon cycle, Nature, 358, 723-727, https://doi.org/10.1038/358723a0, 1992.

Kirchner, J. W.: Aggregation in environmental systems - Part 1: Seasonal tracer cycles quantify young water fractions, but not mean transit times, in spatially heterogeneous catchments, Hydrol. Earth Syst. Sci., 20, 279-297, https://doi.org/10.5194/hess20-279-2016, 2016.

Kirchner, J. W., Finkel, R. C., Riebe, C. S., Granger, D. E., Clayton, J. L., King, J. G., and Megahan, W. F.: Mountain erosion over 10 yr, $10 \mathrm{ky}$, and 10 my time scales, Geology, 29, 591-594, 2001. 
Komada, T., Druffel, E. R. M., and Trumbore, S. E.: Oceanic export of relict carbon by small mountainous rivers, Geophys. Res. Lett., 31, 1-4, https://doi.org/10.1029/2004GL019512, 2004.

Lancaster, S. T. and Bras, R. L.: A simple model of river meandering and its comparison to natural channels, Hydrol. Process., 16, 126, https://doi.org/10.1002/hyp.273, 2002.

Lancaster, S. T. and Casebeer, N. E.: Sediment storage and evacuation in headwater valleys at the transition between debris-flow and fluvial processes, Geology, 35, 1027-1030, https://doi.org/10.1130/G239365A.1, 2007.

Lauer, J. W. and Parker, G.: Modeling framework for sediment deposition, storage, and evacuation in the floodplain of a meandering river: Theory, Water Resour. Res., 44, 1-6, https://doi.org/10.1029/2006WR005528, 2008a.

Lauer, J. W. and Parker, G.: Net local removal of floodplain sediment by river meander migration, Geomorphology, 96, 123-149, https://doi.org/10.1016/j.geomorph.2007.08.003, 2008b.

Lauer, J. W. and Willenbring, J.: Steady state reach-scale theory for radioactive tracer concentration in a simple channel/floodplain system, J. Geophys. Res., 115, F04018, https://doi.org/10.1029/2009JF001480, 2010.

Lawrence, C. R., Harden, J. W., Xu, X., Schulz, M. S., and Trumbore, S. E.: Long-term controls on soil organic carbon with depth and time: A case study from the Cowlitz River Chronosequence, WA USA, Geoderma, 247-248, 73-87, https://doi.org/10.1016/j.geoderma.2015.02.005, 2015.

Leithold, E. L., Blair, N. E., and Perkey, D. W.: Geomorphologic controls on the age of particulate organic carbon from small mountainous and upland rivers, Global Biogeochem. Cy., 20, GB3022, https://doi.org/10.1029/2005GB002677, 2006.

Li, C., Yang, S., Zhao, J. X., Dosseto, A., Bi, L., and Clark, T. R.: The time scale of river sediment source-tosink processes in East Asia, Chem. Geol., 446, 138-146, https://doi.org/10.1016/j.chemgeo.2016.06.012, 2016.

Li, G., Wang, X. T., Yang, Z., Mao, C., West, A. J., and Ji, J.: Dam-triggered organic carbon sequestration makes the Changjiang (Yangtze) river basin (China) a significant carbon sink, J. Geophys. Res.-Biogeo., 120, 39-53, https://doi.org/10.1002/2014JG002646, 2015.

Limaye, A. B. S. and Lamb, M. P.: A vector-based method for bank-material tracking in coupled models of meandering and landscape evolution, J. Geophys. Res.-Earth, 118, 2421-2437, https://doi.org/10.1002/2013jf002854, 2013.

Malmon, D. V., Dunne, T., Reneau, S. L., The, S., and September, N.: Stochastic Theory of Particle Trajectories through Alluvial Valley Floors, J. Geol., 111, 525-542, https://doi.org/10.1086/376764, 2003.

Mantegna, R. N. and Stanley, H. E.: Stochastic process with ultrasound convergence to a Gaussian : truncated Levy flight, Phys. Rev. Lett., 73, 2946-2949, https://doi.org/10.1103/PhysRevLett.73.2946, 1994.

Marriott, S.: Textural analysis and modelling of a flood deposit: River Severn, UK, Earth Surf. Proc. Land., 17, 687-697, 1992.

Martin, E. E., Ingalls, A. E., Richey, J. E., Keil, R. G., Santos, G. M., Truxal, L. T., Alin, S. R., and Druffel, E. R. M.: Age of riverine carbon suggests rapid export of terrestrial primary production in tropics, Geophys. Res. Lett., 40, 5687-5691, https://doi.org/10.1002/2013GL057450, 2013.
Masiello, C. A. and Druffel, E. R. M.: Carbon Isotope Geochemistry of the Santa Clara River, Global Biogeochem. Cy., 15, 407-416, 2001.

Masiello, C. A., Chadwick, O. A., Southon, J., Torn, M. S., and Harden, J. W.: Weathering controls on mechanisms of carbon storage in grassland soils, Global Biogeochem. Cy., 18, 1-9, https://doi.org/10.1029/2004GB002219, 2004.

McGuire, K. J. and McDonnell, J. J.: A review and evaluation of catchment transit time modeling, J. Hydrol., 330, 543-563, https://doi.org/10.1016/j.jhydrol.2006.04.020, 2006.

Meerschaert, M. M., Roy, P., and Shao, Q.: Parameter estimation for exponentially tempered power law distributions, Commun. Stat--Theor. M., 41, 1839-1856, https://doi.org/10.1080/03610926.2011.552828, 2010.

Middelburg, J. J.: A simple rate model for organic matter decomposition in marine sediments, Geochim. Cosmochim. Ac., 53, 1577-1581, https://doi.org/10.1016/0016-7037(89)90239-1, 1989.

Mueller, J. E.: Re-evaluation of the relationship of master streams and drainage basins: Reply, Geol. Soc. Am. Bull, 84, 3127-3130, https://doi.org/10.1130/00167606(1973)84<3127:ROTROM>2.0.CO;2, 1973.

Nagao, S., Usui, T., Yamamoto, M., Minagawa, M., Iwatsuki, T., and Noda, A.: Combined use of D14C and d13C values to trace transportation and deposition processes of terrestrial particulate organic matter in coastal marine environments, Chem. Geol., 218, 63-72, https://doi.org/10.1016/j.chemgeo.2005.01.025, 2005 .

Nakamura, F. and Kikuchi, S.-I.: Transport Processes Using Age Distribution of Floodplain Deposits, Geomorphology, 16, 139145, 1996.

Nitsche, M., Rickenmann, D., Kirchner, J. W., Turowski, J. M., and Badoux, A.: Macroroughness and variations in reach-averaged flow resistance in steep mountain streams, Water Resour. Res., 48, 1-16, https://doi.org/10.1029/2012WR012091, 2012.

Pizzuto, J., Schenk, E. R., Hupp, C. R., Gellis, A., Noe, G., Williamson, E., Karwan, D. L., O’Neal, M., Marquard, J., Aalto, R., and Newbold, D.: Characteristic length scales and time-averaged transport velocities of suspended sediment in the mid-Atlantic Region, USA, Water Resour. Res., 50, 790-805, https://doi.org/10.1002/2013WR014485, 2014.

Pizzuto, J., Keeler, J., Skalak, K., and Karwan, D.: Storage filters upland suspended sediment signals delivered from watersheds, Geology, 44, G38170.1, https://doi.org/10.1130/G38170.1, 2017.

Pizzuto, J. E.: Sediment diffusion during overbank flows, Sedimentology, 34, 301-317, https://doi.org/10.1111/j.13653091.1987.tb00779.x, 1987.

Ponton, C., West, A. J., Feakins, S. J., and Galy, V.: Leaf wax biomarkers in transit record river catchment composition, Geophys. Res. Lett., 41, 6420-6427, https://doi.org/10.1002/2014GL061328, 2014.

Rosenheim, B. E., Roe, K. M., Roberts, B. J., Kolker, A. S., Allison, M. A., and Johannesson, K. H.: River discharge influences on particulate organic carbon age structure in the Mississippi/Atchafalaya River System, Global Biogeochem. Cy., 27, 154-166, https://doi.org/10.1002/gbc.20018, 2013.

Rosiński, J.: Tempering stable processes, Stoch. Proc. Appl., 117, 677-707, https://doi.org/10.1016/j.spa.2006.10.003, 2007. 
Sadler, P. M.: Sediment accumulation rates and the completeness of stratigraphic sections, J. Geol., 89, 569-584, 1981.

Schefuß, E., Eglinton, T. I., Spencer-Jones, C. L., Rullkötter, J., De Pol-Holz, R., Talbot, H. M., Grootes, P. M., and Schneider, R. R.: Hydrologic control of carbon cycling and aged carbon discharge in the Congo River basin, Nat. Geosci., 9, 687-690, https://doi.org/10.1038/ngeo2778, 2016.

Schmidt, M. W. I., Torn, M. S., Abiven, S., Dittmar, T., Guggenberger, G., Janssens, I. A., Kleber, M., Kögel-Knabner, I., Lehmann, J., Manning, D. A. C., Nannipieri, P., Rasse, D. P., Weiner, S., and Trumbore, S. E.: Persistence of soil organic matter as an ecosystem property, Nature, 478, 49-56, https://doi.org/10.1038/nature10386, 2011.

Schwenk, J., Lanzoni, S., and Foufoula-Georgiou, E.: The life of a meander bend: Connecting shape and dynamics via analysis of a numerical model, J. Geophys. Res.-Earth, 120, 690-710, https://doi.org/10.1002/2014JF003252, 2015.

Smith, J. C., Galy, A., Hovius, N., Tye, A. M., Turowski, J. M., and Schleppi, P.: Runoff-driven export of particulate organic carbon from soil in temperate forested uplands, Earth Planet. Sc. Lett., 365, 198-208, https://doi.org/10.1016/j.epsl.2013.01.027, 2013.

Stallard, R. F.: Terrestrial sedimentation and the carbon cycle: Coupling weathering and erosion to carbon burial, Global Biogeochem. Сy., 12, 231-257, https://doi.org/10.1029/98GB00741, 1998.

Tal, M. and Paola, C.: Dynamic single-thread channels maintained by the interaction of flow and vegetation, Geology, 35, 347-350, https://doi.org/10.1130/G23260A.1, 2007.

Tao, S., Eglinton, T. I., Montluçon, D. B., McIntyre, C., and Zhao, M.: Pre-aged soil organic carbon as a major component of the Yellow River suspended load: Regional significance and global relevance, Earth Planet. Sc. Lett., 414, 77-86, https://doi.org/10.1016/j.epsl.2015.01.004, 2015.

Torn, M. S., Trumbore, S. E., Chadwick, O. A., Vitousek, P. M., and Hendricks, D. M.: Mineral control of soil organic carbon storage and turnover, Nature, 389, 3601-3603, https://doi.org/10.1038/38260, 1997.
Townsend-Small, A., Noguera, J. L., McClain, M. E., and Brandes, J. A.: Radiocarbon and stable isotope geochemistry of organic matter in the Amazon headwaters, Peruvian Andes, Global Biogeochem. Cy., 21, 1-9, https://doi.org/10.1029/2006GB002835, 2007.

Turowski, J. M., Hilton, R. G., and Sparkes, R.: Decadal carbon discharge by a mountain stream is dominated by coarse organic matter, Geology, 44, 27-30, https://doi.org/10.1130/G37192.1, 2016.

Voss, B. M.: Spatial and temporal dynamics of biogeochemical processes in the Fraser River, Canada: A coupled organic-inorganic perspective, $\mathrm{PhD}$ thesis, Woods Hole Oceanographic Institution, 2014.

Wang, X., Ma, H., Li, R., Song, Z., and Wu, J.: Seasonal fluxes and source variation of organic carbon transported by two major Chinese Rivers: The Yellow River and Changjiang (Yangtze) River, Global Biogeochem. Cy., 26, 1-10, https://doi.org/10.1029/2011GB004130, 2012.

Williams, G. P.: River Meanders and Channel Size, J. Hydrol., 88, 147-164, 1986.

Wittmann, H., Von Blanckenburg, F., Dannhaus, N., Bouchez, J., Gaillardet, J., Guyot, J. L., Maurice, L., Roig, H., Filizola, N., and Christl, M.: A test of the cosmogenic $10 \mathrm{Be}$ (meteoric)/9Be proxy for simultaneously determining basin-wide erosion rates, denudation rates, and the degree of weathering in the Amazon basin, J. Geophys. Res.-Earth Surface, 120, 2498-2528, https://doi.org/10.1002/2015JF003581, 2015.

Wittmann, H., Malusà, M. G., Resentini, A., Garzanti, E., and Niedermann, S.: The cosmogenic record of mountain erosion transmitted across a foreland basin: Source-to-sink analysis of in situ $10 \mathrm{Be}, 26 \mathrm{Al}$ and $21 \mathrm{Ne}$ in sediment of the Po river catchment, Earth Planet. Sc. Lett., 452, 258-271, https://doi.org/10.1016/j.eps1.2016.07.017, 2016. 